U.S. CLIVAR Hurricanes

COLLECTION

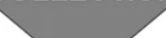

\title{
Testing the Performance of Tropical Cyclone Genesis Indices in Future Climates Using the HiRAM Model
}

\author{
SUZANA J. CAMARGO \\ Lamont-Doherty Earth Observatory, Columbia University, Palisades, New York \\ MiCHAEL K. TIPPETT \\ Department of Applied Physics and Applied Mathematics, Columbia University, New York, New York, and \\ Center of Excellence for Climate Change Research, King Abdulaziz University, Jeddah, Saudi Arabia \\ ADAM H. SOBEL \\ Department of Earth and Environmental Sciences, and Department of Applied Physics and Applied \\ Mathematics, Columbia University, New York, New York \\ GABriel A. VeCCHI AND Ming ZHAO \\ NOAA/Geophysical Fluid Dynamics Laboratory, Princeton, New Jersey
}

(Manuscript received 19 August 2013, in final form 4 September 2014)

\begin{abstract}
Tropical cyclone genesis indices (TCGIs) are functions of the large-scale environment that are designed to be proxies for the probability of tropical cyclone (TC) genesis. While the performance of TCGIs in the current climate can be assessed by direct comparison to TC observations, their ability to represent future TC activity based on projections of the large-scale environment cannot. Here the authors examine the performance of TCGIs in high-resolution atmospheric model simulations forced with sea surface temperatures (SST) of future, warmer climate scenarios. They investigate whether the TCGIs derived for the present climate can, when computed from large-scale fields taken from future climate simulations, capture the simulated global mean decreases in TC frequency. The TCGIs differ in their choice of environmental predictors, and several choices of predictors perform well in the present climate. However, some TCGIs that perform well in the present climate do not accurately reproduce the simulated future decrease in TC frequency. This decrease is captured when the humidity predictor is the column saturation deficit rather than relative humidity. Using saturation deficit with relative SST as the other thermodynamic predictor overpredicts the TC frequency decrease, while using potential intensity in place of relative SST as the other thermodynamic predictor gives a good prediction of the decrease's magnitude. These positive results appear to depend on the spatial and seasonal patterns in the imposed SST changes; none of the indices capture correctly the frequency decrease in simulations with spatially uniform climate forcings, whether a globally uniform increase in SST of $2 \mathrm{~K}$, or a doubling of $\mathrm{CO}_{2}$ with no change in SST.
\end{abstract}

\section{Introduction}

It is critically important to understand how greenhouse gas-induced climate change will influence tropical cyclone

Corresponding author address: Suzana J. Camargo, LamontDoherty Earth Observatory, Columbia University, P.O. Box 1000, Palisades, NY 10960.

E-mail: suzana@1deo.columbia.edu activity. To do this, we have to first know how the largescale climate will change and then how the large-scale climate changes will influence tropical cyclones (TCs). We focus here on the second question, given an answer to the first.

Most model projections for the twenty-first-century climate are computed with relatively low-resolution models. Most of the model simulations in phase 5 of the Coupled Model Intercomparison Project (CMIP5), for example, 
TABLE 1. HiRAM simulations used in this study, including forcing, name, and duration.

\begin{tabular}{|c|c|c|c|}
\hline Type & Name & Abbreviation & Duration \\
\hline Climatological SST & Climatology & $\mathrm{CL}$ & $25 \mathrm{yr}$ \\
\hline Multimodel ensemble mean SST anomalies & Warm & W & $20 \mathrm{yr}$ \\
\hline $\begin{array}{l}\text { SST anomalies Canadian Centre for Climate Modeling and } \\
\text { Analysis (CCCMA) model }\end{array}$ & Warm CCCMA & WC & $10 \mathrm{yr}$ \\
\hline SST anomalies ECHAM5 model & Warm ECHAM5 & WE & $10 \mathrm{yr}$ \\
\hline SST anomalies GFDL Climate Model, version 2.1 (CM2.1) & Warm GFDL 2.1 & WG & $10 \mathrm{yr}$ \\
\hline SST anomalies GFDL CM2.0 model & Warm GFDL 2.0 & W0 & $10 \mathrm{yr}$ \\
\hline SST anomalies HadCM3 model & Warm HadCM3 & W3 & $10 \mathrm{yr}$ \\
\hline $\begin{array}{l}\text { SST anomalies Hadley Centre Global Environment Model, } \\
\text { version } 1 \text { (HadGEM1) }\end{array}$ & Warm HadGEM1 & W1 & $10 \mathrm{yr}$ \\
\hline $\begin{array}{l}\text { SST anomalies Model for Interdisciplinary Research on } \\
\text { Climate (MIROC) }\end{array}$ & Warm MIROC & WO & $10 \mathrm{yr}$ \\
\hline $\begin{array}{l}\text { SST anomalies Meteorological Research Institute } \\
\text { (MRI) model }\end{array}$ & Warm MRI & WI & $10 \mathrm{yr}$ \\
\hline 2 times $\mathrm{CO}_{2}$ & $2 \times \mathrm{CO}_{2}$ & $2 \times \mathrm{CO}_{2}$ & $25 \mathrm{yr}$ \\
\hline
\end{tabular}

have horizontal grid spacings of order $100 \mathrm{~km}$ or greater. While these low-resolution models are able to simulate tropical cyclone-like structures that have grossly similar properties to observed TCs (Bengtsson et al. 1982; Vitart et al. 1997; Camargo et al. 2005, 2007b), these low-resolution model cyclones are inadequate for detailed studies of the relation of TCs to climate. The cyclones are too large and too weak, and, in most cases, their climatological distributions in space and time of year are significantly biased (Walsh et al. 2013; Camargo 2013; Tory et al. 2013a,b). An emerging generation of high-resolution coupled climate models is enabling the exploration of the climate response of TCs more directly (e.g., Roberts et al. 2009; Delworth et al. 2012; Bell et al. 2013; Kim et al. 2014), yet these high-resolution models represent a small fraction of the climate models presently used around the globe.

Many methods for examining future tropical cyclone activity involve downscaling the results of global climate models, using the models to predict changes in the large-scale atmospheric and oceanic environmental fields that are statistically associated with tropical cyclone activity, and inferring likely changes in tropical cyclone statistics from those environmental fields, rather than direct simulation by the climate model. Since low-resolution climate models have better skill in simulating the environmental fields than in simulating TC-like structures themselves (e.g., Camargo 2013), these strategies make better use of the climate models. One possibility is to use the large-scale fields of the global models to force regional climate models (Landman et al. 2005; Camargo et al. 2007a; Knutson et al. 2008). Another possibility is to use a hybrid dynamical-statistical model (e.g., Vecchi et al. 2011) as well as a dynamical downscaling model that generates synthetic storms based on environmental fields output from the models (Emanuel et al. 2006; Emanuel 2006, 2013). Still another option for downscaling is to use statistical models for basin-integrated activity (Villarini and Vecchi 2012, 2013).

Another possibility, and the one explored here, is to relate the models' projections to tropical cyclone changes using local (rather than basin-integrated) relationships between the environmental fields and TC activity in the recent historical climate. A local relationship between environmental factors and the probability of tropical cyclogenesis is known as a genesis index.

Gray (1979) developed the first genesis index. Gray's index is not appropriate to explore TC activity in the future, as it uses a fixed sea surface temperature (SST) threshold. To the extent that such a threshold is a good predictor, we expect that it will increase as the climate warms (e.g., Johnson and Xie 2010) since relative SST (the difference between local SST and the tropical mean, or another reference, such as the tropical mean upper tropospheric temperature) is a better predictor than absolute SST (Vecchi and Soden 2007; Swanson 2008; Ramsay and Sobel 2011). Since then, many other indices have been developed. Most of these improve on Gray's original index by replacing the fixed SST threshold with thermodynamic predictors more appropriate for handling climate change. The first application of a genesis index to climate change appeared in Ryan et al. (1992), where Gray's index was applied to the environmental fields of a global climate model in present and future climate simulations.

One of the most widely used indices is the genesis potential index (GPI) developed by Emanuel and Nolan 
(a) First Position Density - HIRAM

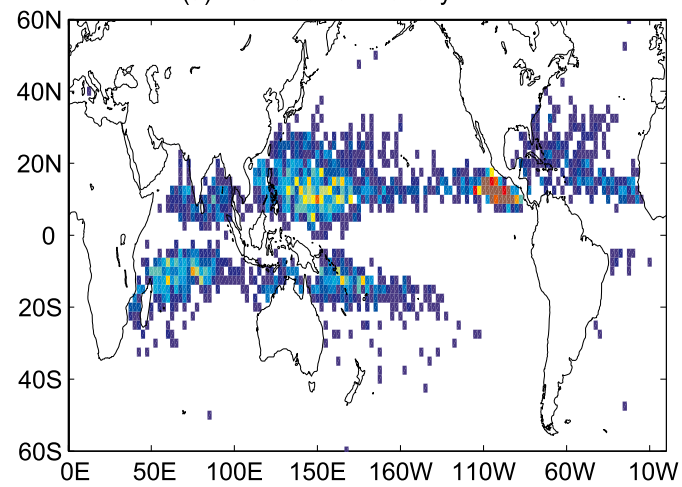

(c) First Position Density - Observations

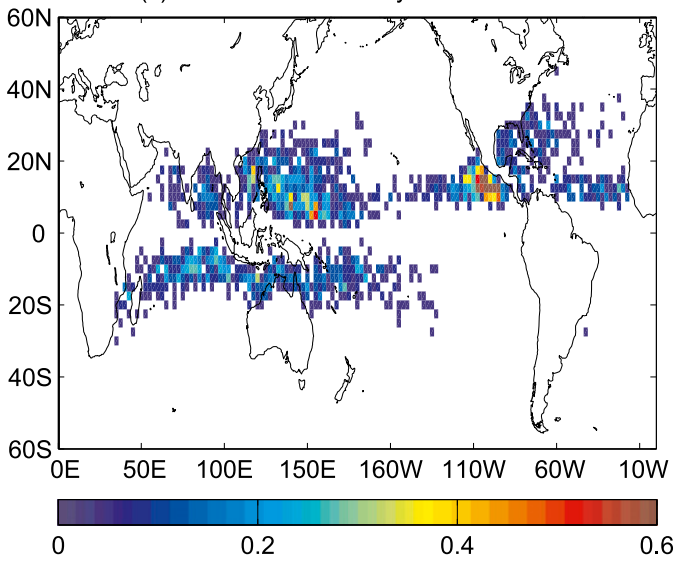

(c) Tracks HIRAM

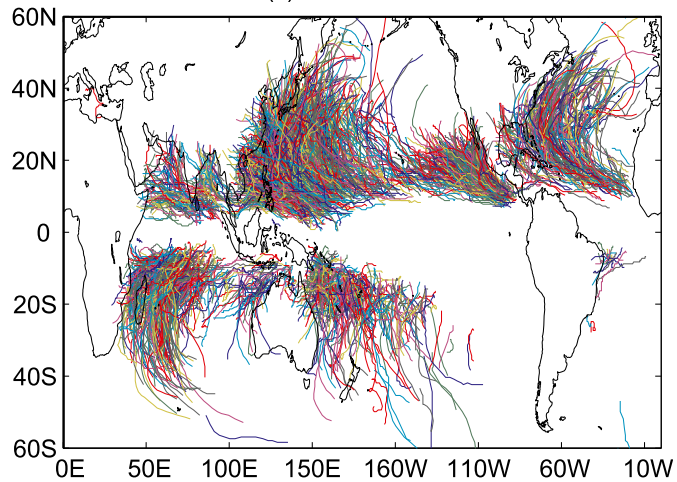

(d) Tracks Observations

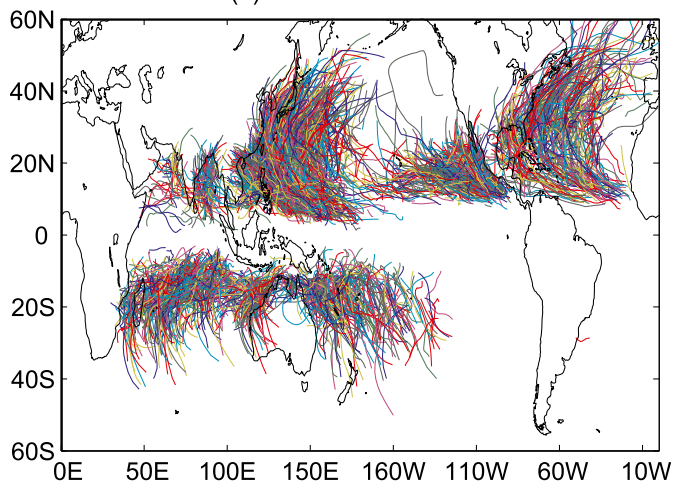

FIG. 1. First-position density (number of geneses per year) and tracks (a),(b) for the control simulation of HiRAM and (c),(d) in observations. The control simulation is forced with climatological SST for 25 years, and the observed data used is for the period 1981-2005.

(2004). It replaces SST entirely, using potential intensity instead. The GPI has been used in applications on various time scales, from intraseasonal to climate change (Camargo et al. 2007a, 2009; Vecchi and Soden 2007; Nolan et al. 2007; Lyon and Camargo 2009; Yokoi et al. 2009; Yokoi and Takayabu 2009; Camargo 2013). More recently, Emanuel (2010) modified his original index, using a variable associated with the entropy saturation deficit in place of the relative humidity parameter used in the original index. While having a similar spatial and temporal distribution in the present climate, the humidity saturation deficit differs from relative humiditybeing the difference between the specific humidity and its saturation value, rather than the ratio, and thus increasing systematically with warming if relative humidity remains constant-in a way that is consequential, and apparently better, for capturing the greenhouse gasforced climate change influence on TCs. Many other alternative indices have been developed, using different predictors or different functional dependences in their indices (DeMaria et al. 2001; Royer et al. 1998; Sall et al.
2006; Bye and Keay 2008; Kotal et al. 2009; Murakami and Wang 2010; Bruyère et al. 2012; Waters et al. 2012; Tang and Emanuel 2012; Holland and Bruyère 2014; Tang and Camargo 2014). A recent intercomparison of various genesis indices, including the Tippett et al. (2011) index used here, is given in Menkes et al. (2012).

Our goal here is to evaluate how well tropical cyclone indices developed in the present climate are able to predict changes in tropical cyclone frequency in future climates. These indices are partly empirical. The predictors are selected based on our current physical understanding of the factors that control genesis; but that understanding is imperfect, and the relationships between the predictors and the index are found using data from the present climate. Thus, it is possible that they will fail to capture the influence of future climate changes on TCs. We cannot perform empirical tests of the indices' ability to capture these changes using observations, since there are no observations of future tropical cyclone activity. As an alternative, we use a perfect model framework to test our index methodology. 
(a) NTC Southern Hemisphere

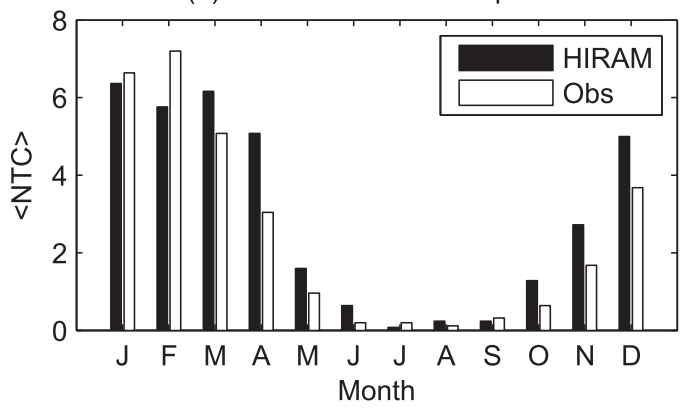

(c) NTC South Indian

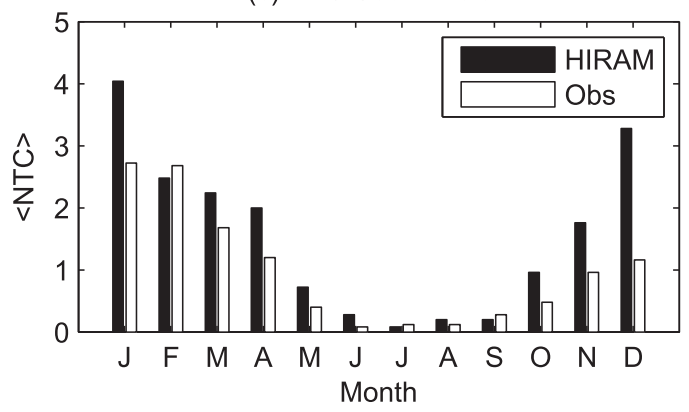

(e) NTC Western North Pacific

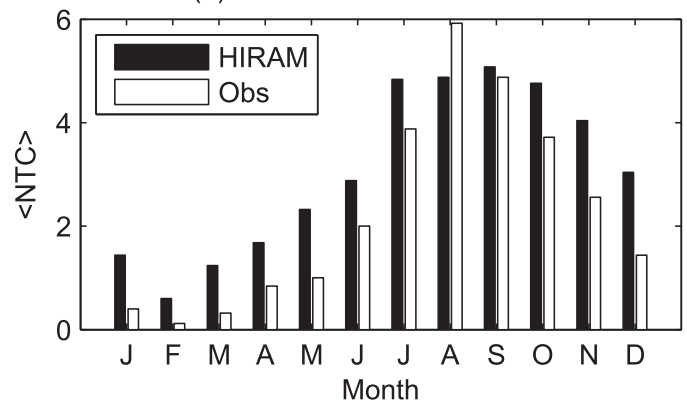

(b) NTC Northern Hemisphere

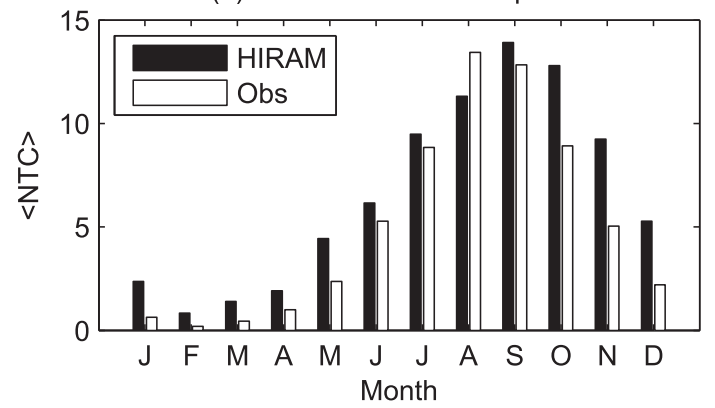

(c) NTC Australia

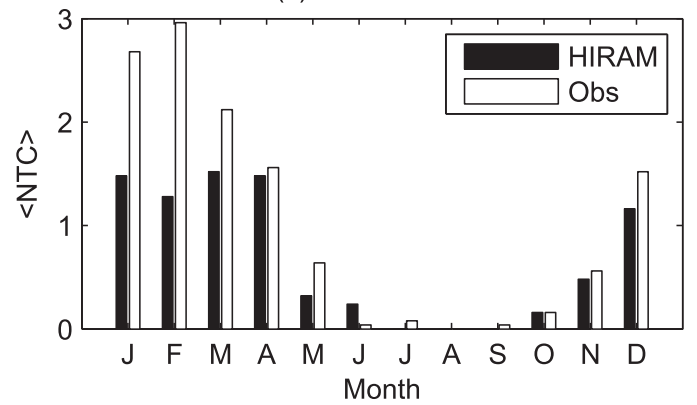

(f) NTC North Atlantic

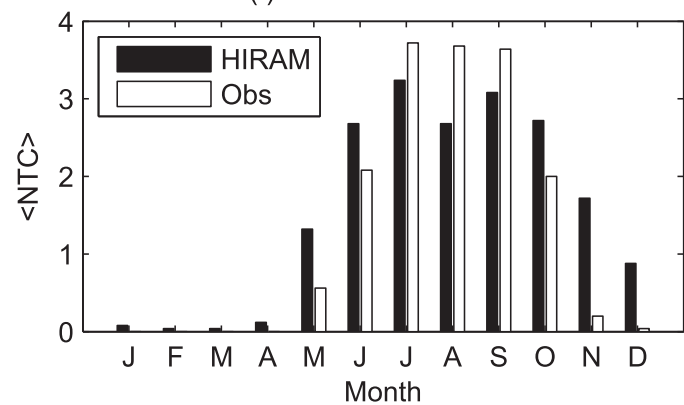

FIG. 2. Mean NTC per month for the HiRAM climatological simulation and observations (1981-2005) in the (a) Southern Hemisphere, (b) Northern Hemisphere, (c) south Indian Ocean, (d) Australian region, (e) western North Pacific, and (f) North Atlantic.

The decrease in TC frequency in the future is projected by an overwhelming number of climate models, the behavior of the chosen model is expected to be very typical. Therefore, in the absence of future observations, we think our approach is a valid one. We are currently applying the procedure described here to other highresolution climate models to further test this approach in a multimodel setting. One of the only results where an increase in global TC frequency was projected was obtained by applying a dynamical downscaling to the CMIP5 models (Emanuel 2013). However, the same downscaling applied to the CMIP3 models also projected a decrease in global TC frequency (Emanuel et al. 2006), in agreement with other models. In summary, we chose a state-of-the-art high-resolution climate model that projects a decrease in global TC frequency in the future to use in our perfect model framework.
Specifically, we use the Geophysical Fluid Dynamics Laboratory (GFDL) High Resolution Atmospheric Model (HiRAM) forced with specified SST at 50-km resolution. This model has been extensively examined in the present and future climates. It has been shown

TABLE 2. Domain definitions used for basin integrations. All Southern (Northern) Hemisphere basins are defined in oceanic regions from the equator to $40^{\circ} \mathrm{S}\left(40^{\circ} \mathrm{N}\right)$.

\begin{tabular}{ll}
\hline \hline South Indian & $20^{\circ}-105^{\circ} \mathrm{E}$ \\
Australian & $105^{\circ}-165^{\circ} \mathrm{E}$ \\
South Pacific & $165^{\circ} \mathrm{E}-70^{\circ} \mathrm{W}$ \\
North Indian & $40^{\circ}-100^{\circ} \mathrm{E}$ \\
Western North Pacific & $100^{\circ} \mathrm{E}-180^{\circ}$ \\
Central North Pacific & $180^{\circ}-140^{\circ} \mathrm{W}$ \\
Eastern North Pacific (ENP) & $140^{\circ} \mathrm{W}$ to American coast \\
North Atlantic & American coast to African coast \\
South Atlantic & American coast to African coast \\
\hline
\end{tabular}


to simulate both the current climatological global distribution of tropical cyclone activity and recent historical interannual variations in Atlantic tropical cyclone activity well. It predicts a decrease in global tropical cyclone frequency in a warmer climate, similar to most other comparable models (Knutson et al. 2010).

Our procedure is as follows:

(i) Use the model's own TCs and large-scale environmental fields, taken from a control simulation, to derive a tropical cyclone genesis index.

(ii) Compute the resulting index from model environmental fields taken from a simulation of a warmer climate.

(iii) Compare the future changes in the indices to future changes in the model's own tropical cyclone frequency.

We use the technique developed by Tippett et al. (2011) to generate and test a number of different tropical cyclone genesis indices in this fashion. The indices differ in the predictors that are used. While our interest here is in the changes due to warming, our procedure also ensures that the indices capture the climatological spatial distribution and seasonal cycle of tropical cyclogenesis in the control simulation from which the index is derived. This feature is an important difference between our method and those involving statistical models, which are designed only to capture temporal variations in basin-integrated activity for a single basin. Each method has its advantages; the advantage of the index methodology is that, being based on local relationships between the probability of genesis and the environment, it is closer to a physical theory for genesis (though still not quite being one, since it is partly empirical). An index that captures the seasonal cycle, global spatial distribution, and temporal changes in genesis frequency everywhere-if one were to existwould have more explanatory power than one that captures only temporal changes in the basin-integrated frequency for a single basin. If the goal is only to predict variations in basin-integrated activity for one basin, a model designed solely for that purpose may be best. Our approach, instead, tests our understanding of the local physics of genesis, to the extent that the indices represent that.

In section 2, we summarize the procedure used by Tippett et al. (2011) to construct a tropical cyclone genesis index (TCGI). In section 3, we describe the datasets, HiRAM, and the model simulations. A summary of the TC activity in HiRAM is given in section 4. We apply the TCGI to HiRAM in section 5. Various alternative indices obtained using HiRAM environmental

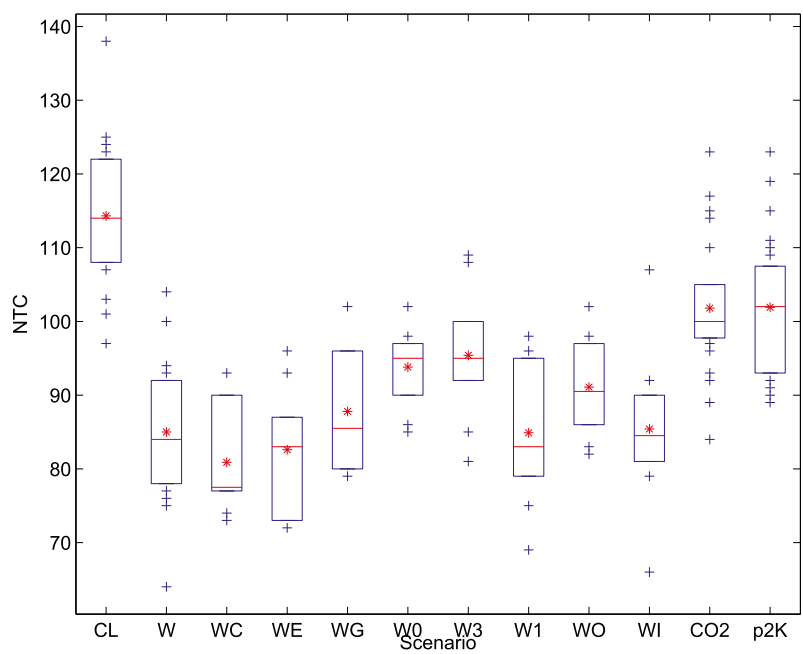

FIG. 3. Global number of TCs per year in each of the HiRAM simulations. The label "CO2" is for the $2 \times \mathrm{CO} 2$ simulation.

fields and TCs are tested in section 6 . In section 7, we discuss our results.

\section{Developing TCGI}

\section{a. Overview of the methodology}

One objective of Tippett et al. (2011) was to develop a TCGI using a robust, objective, and easily reproducible procedure. Such a procedure allows the index to be rederived easily when new datasets become available for either the environmental fields or tropical cyclones or if new hypotheses about which environmental fields should be used as predictors are developed. The statistical method used is Poisson regression. The TCGI in Tippett et al. (2011) was constructed using the observed climatology of tropical cyclogenesis and largescale variables from the 40-yr European Centre for Medium-Range Weather Forecasts (ECMWF) interim reanalysis (ERA-40) and National Centers for Environmental Protection (NCEP)-National Center for Atmospheric Research (NCAR) reanalysis, as well as retrievals of column water vapor from satellite passive microwave observations.

The regression methodology is objective and provides a framework for the selection of the climate variables to be used in the index. This method led us to select four environmental variables for the index similar but not identical to those used by Emanuel and Nolan (2004): low-level absolute vorticity, relative humidity, relative SST (difference between the SST and mean tropical SST), and vertical wind shear. One result of Tippett et al. (2011) is that the sensitivity of genesis on low-level absolute vorticity saturates after the vorticity exceeds a 
(a) Warm

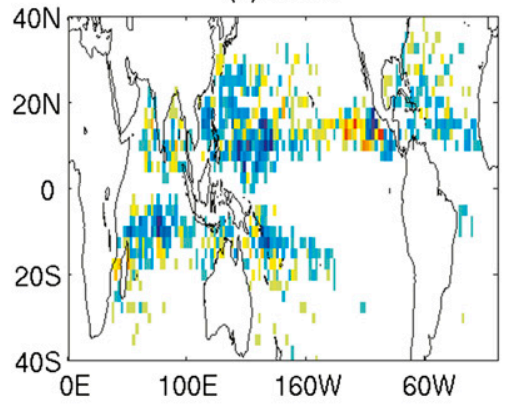

(d) GFDL

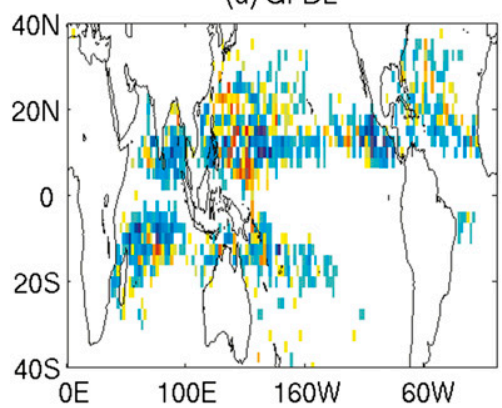

(g) HadGEM1

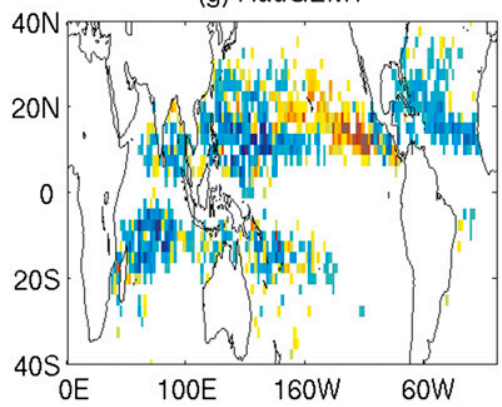

(b) CCCMA

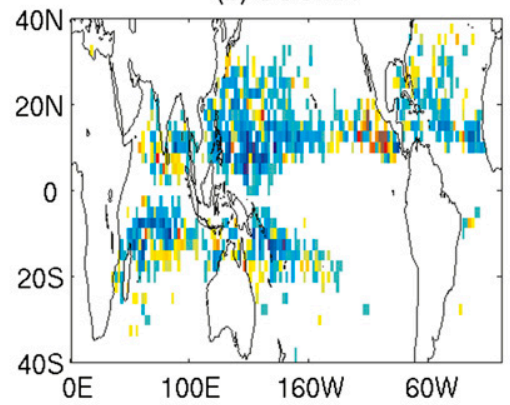

(e) GFDL CM20

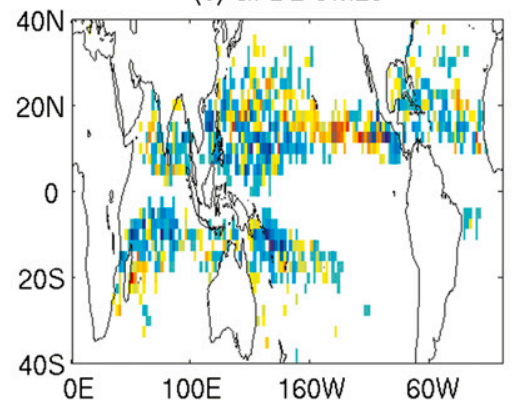

(h) MIROC

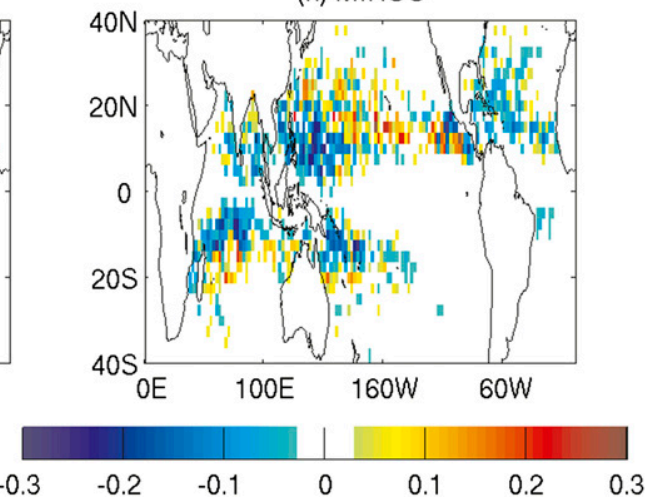

(c) Echam5

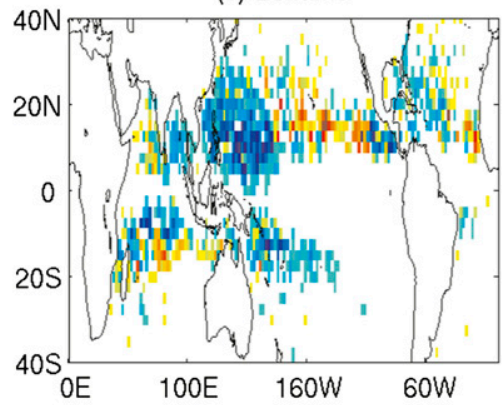

(f) $\mathrm{HadCM} 3$

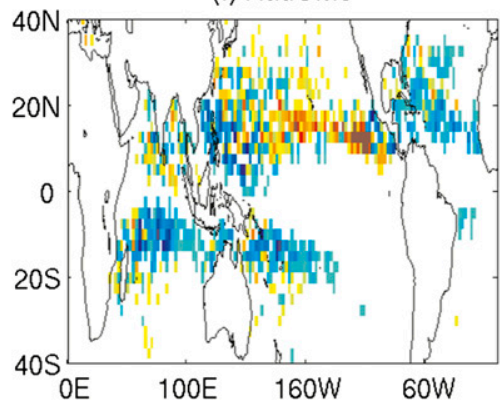

(i) MRI

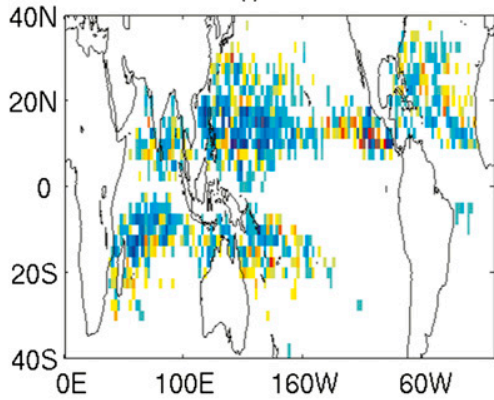

FIG. 4. Difference in the first-position density climatology between the future HiRAM simulations with different SST anomalies and the present. The first-position density was calculated using the reanalysis grid, as in Fig. 1a, and a Gaussian filter using a standard deviation value of 0.5 over three rows and columns.

threshold; using a "clipped vorticity" parameter to account for this saturation leads to a better fit of the index to the genesis observations. Although the index was fit only to the climatological data, it reproduces some aspects of the interannual variability reasonably well. The same procedure, with different predictors and predictands, was recently applied successfully to describe the relationship of tornado activity over the United States to environmental variables (Tippett et al. 2012, 2014), as well as to hail occurrence (Allen et al. 2014, manuscript submitted to J. Adv. Model. Earth Syst.).

The fact that the index can be easily rederived allows us to customize it to HiRAM (or any other model or reanalysis dataset). An index derived from TC observations and reanalysis fields will not perform well when used with TCs and environmental variables from a model, since the relationships between environment and TCs in the model may differ from those in the real atmosphere. To address this problem, we can simply rederive our index using both TCs and large-scale fields from the model itself. In this case, we know that the resulting index will be faithful to the model's own relationship between environment and TCs, at least in the simulation from which it was derived. If the resulting index, when computed from the warmer climate simulation, successfully predicts changes in TC genesis statistics, 
it increases our confidence in both the index methodology and our ability to understand the reasons for the $\mathrm{TC}$ changes in the simulated warmer climate.

\section{b. Specifics}

For each grid cell (on a latitude-longitude grid chosen to match the environmental data) and calendar month, we fit the index to the total number of TCs during a $40-y r$ period (in the case of the reanalysis index). We use a log-linear model such that the logarithm of the expected number of TCs is linearly related to the index derived from the climate variables. We include a term that takes into account the convergence of the meridians so that the units of our index are the number of TCs per unit surface area. We use the maximized log likelihood and the Akaike information criteria (Akaike 1973) to measure the model fit, and attempt to avoid the selection of useless predictors and overfitting. We use a quasiPoisson method in which the coefficient estimates are the same as in Poisson regression, but their standard errors are inflated to reflect overdispersion. A characteristic of the Poisson regression model is that the coefficients of the regression can be interpreted as sensitivities.

The form of the Poisson regression model is, for example,

$$
\mu=\exp \left(b+b_{\eta} \eta+b_{H} H+b_{T} T+b_{V} V+\log \cos \phi\right),
$$

where $\mu$ is the expected number of tropical cyclones per month in a 40-yr climatological period, $b$ is a constant term, and $\phi$ is latitude. Here $\eta, H, T$, and $V$ are, respectively, the absolute vorticity at $850 \mathrm{hPa}$ in $10^{5}$, the column-relative humidity in percent, relative SST in ${ }^{\circ} \mathrm{C}$ (difference between the SST at each grid point and the mean tropical SST), and vertical wind shear between $850-$ and $200-\mathrm{hPa}$ levels in $\mathrm{m} \mathrm{s}^{-1}$. The best fit obtained in Tippett et al. (2011), using reanalysis fields to compute these predictors, together with observed TC climatology data, has the following coefficients: $b=-11.96, b_{\eta}=1.12, b_{H}=0.12, b_{T}=0.46$, and $b_{V}=$ -0.13 (also given in Table 3 ). Here, we will consider these same predictors but will also consider possible substitutes for $H$ and $T$.

We first apply the TCGI obtained from reanalysis (TCGI-R) to HiRAM fields and compare it with the number of TCs in HiRAM. In the second part of the analysis, we will derive the index from HiRAM fields and its TCs in the present climate, performing the Poisson regression on those quantities to obtain a new TCGI from HiRAM itself (TCGI-H). Having derived this index from the HiRAM control simulation forced with historical climatological SST, we then compute the index using fields from HiRAM simulations with warmer (a) TCGI-R HIRAM Climatology

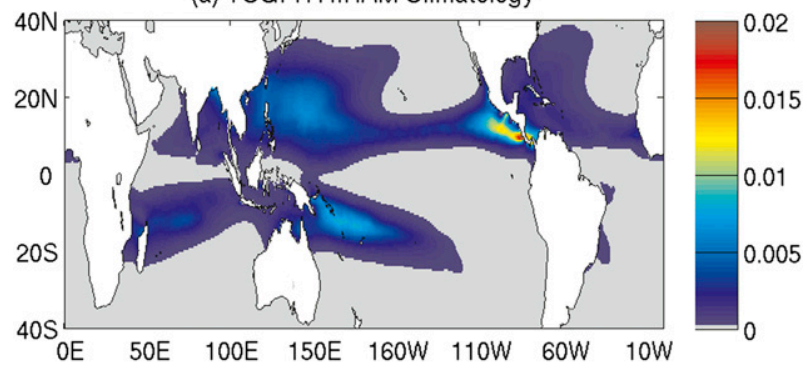

(b) TCGI-R NCEP

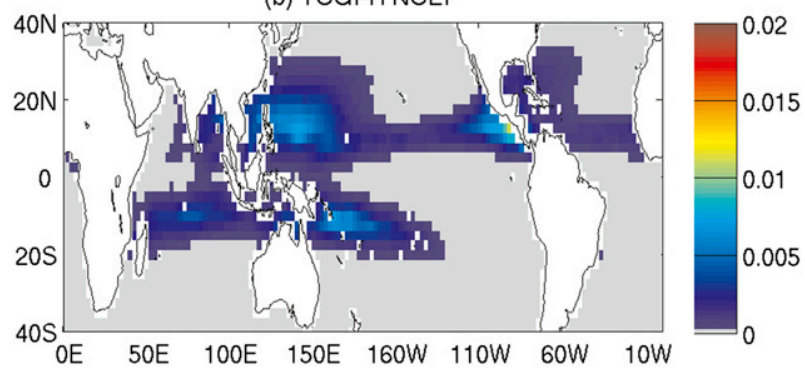

(c) TCGI-R ERA40

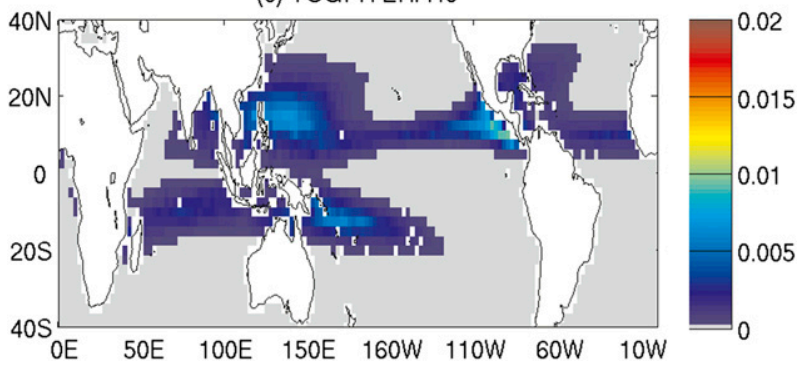

FIG. 5. Climatology of TCGI-R per year for (a) HiRAM climatology, (b) NCEP reanalysis, and (c) ERA-40. The values of TCGI for HiRAM integrated give the number of genesis events per year. The values of the TCGI for both reanalyses were normalized by the ratio of the grid sizes between the reanalysis and HiRAM for a direct comparison with the HiRAM TCGI-R.

SST and assess whether the index captures the TC frequency changes simulated directly by the model. We repeat this procedure varying the predictors. We then derive indices using environmental fields and TCs taken directly from the warmer, future climate simulations in HiRAM in order to examine the changes in the index that result.

\section{Data and HiRAM models and simulations}

The observed tropical cyclone data are from the best track datasets of the National Hurricane Center (NHC) for the North Atlantic and eastern North Pacific (NHC 2013) and the Joint Typhoon Warning Center (JTWC) for the North Indian, western North Pacific, and Southern Hemisphere (JTWC 2013). The reanalysis fields used to 
(a) Warm

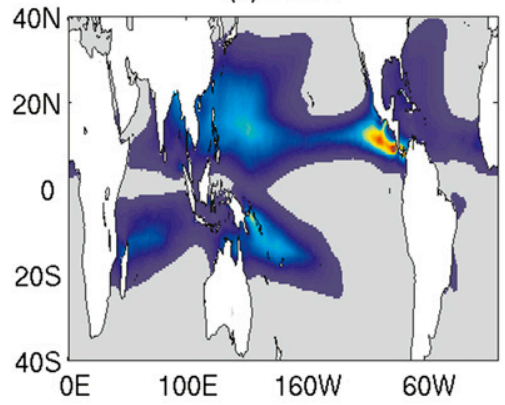

(d) GFDL21

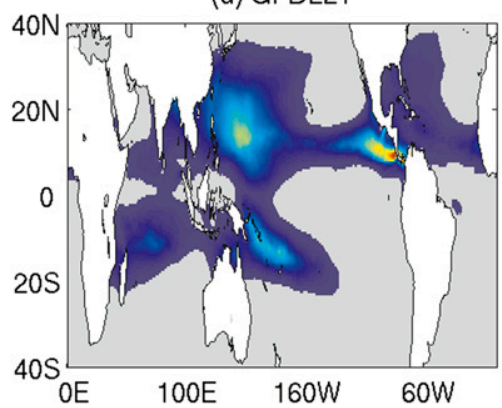

(g) HadGEM1

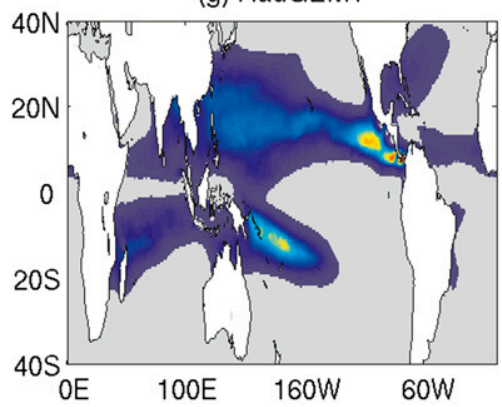

(b) CCCMA

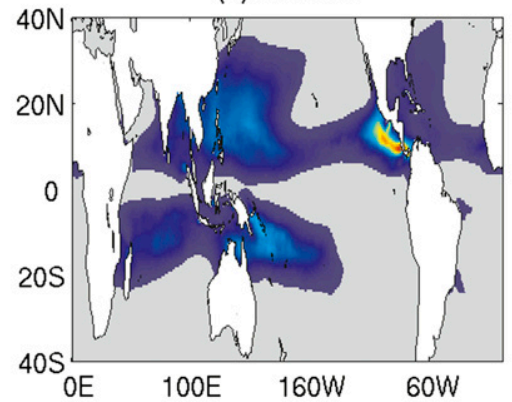

(e) GFDL20

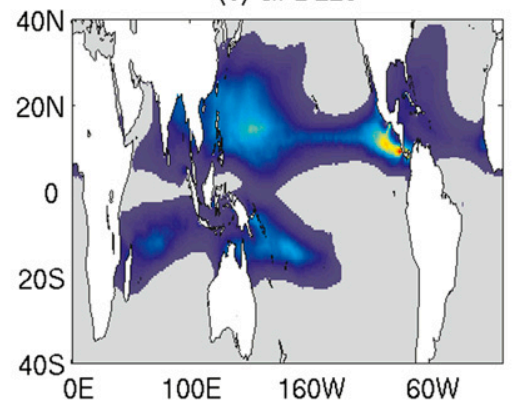

(h) MIROC

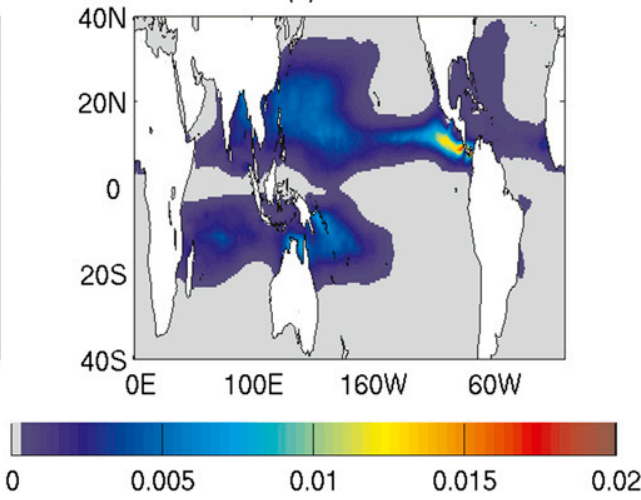

(c) Echam5

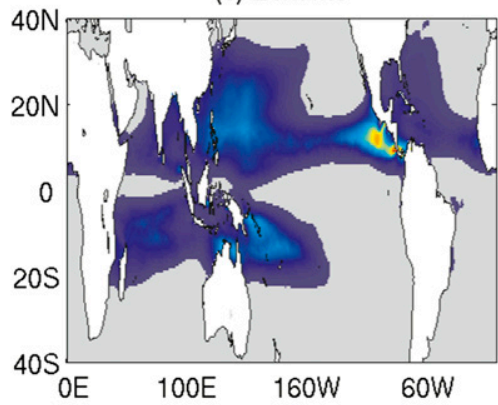

(f) $\mathrm{HadCM} 3$

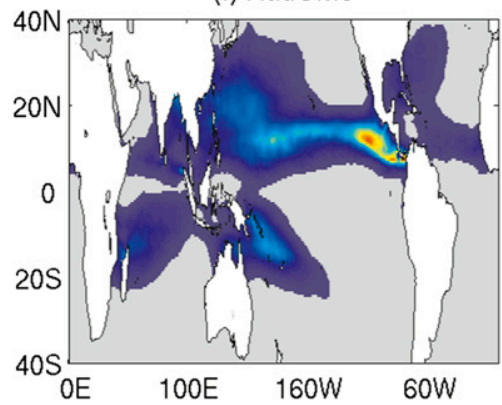

(i) MRI

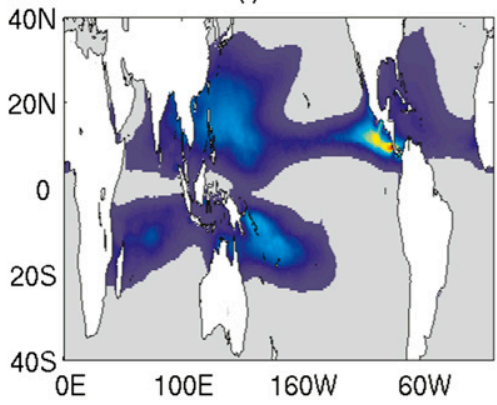

FIG. 6. Climatology of TCGI-R for HiRAM runs forced with different SST anomalies, as described in Table 1.

calculate the TCGI are from the NCEP-NCAR reanalysis (Kalnay et al. 1996; Kistler et al. 2001) and the ERA-40 (Uppala et al. 2005).

The column-integrated relative humidity for observations and HiRAM were calculated following the procedure developed in Bretherton et al. (2004). In the case of observations, the observed retrievals of columnintegrated water vapor $W$ for all available Special Sensor Microwave Imager (SSM/I; Wentz and Spencer 1998), is as described in detail in Tippett et al. (2011). The column-relative humidity is calculated by first calculating the daily averaged saturation water vapor path $W_{*}$ using reanalysis data. The daily column-relative humidity is defined as the ratio $W / W_{*}$; monthly means and climatological values are then calculated.
HiRAM is a modified version of the GFDL Atmospheric Model, version 2.1 (AM2.1), as described in detail in Zhao et al. (2009). The version used here has $50-\mathrm{km}$ horizontal grid spacing. The tropical cyclone activity in this model has been examined in many studies, including Zhao et al. $(2009,2010)$ and Zhao and Held (2010, 2012). The climatological TC activity in HiRAM is similar to that in the observations in its spatial and temporal characteristics, although the storm frequency is lower than observed in the North Atlantic, eastern North Pacific, and south Indian basins and higher than observed in the western North Pacific and South Pacific. HiRAM is able to reproduce the interannual variability and trends of the TC activity in the period 1981-2005 in the North Atlantic with a high degree of 
(a) Warm

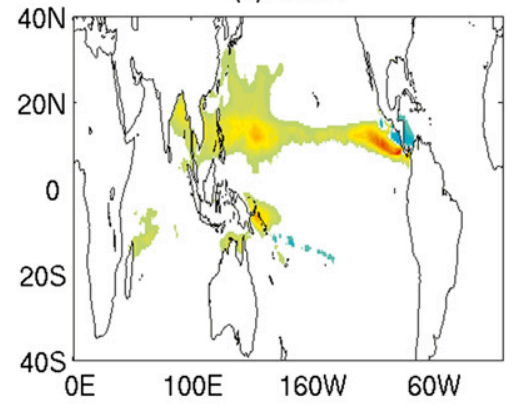

(d) GFDL21

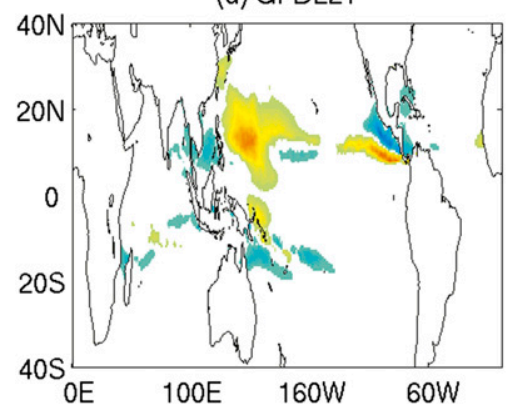

(g) HadGEM1

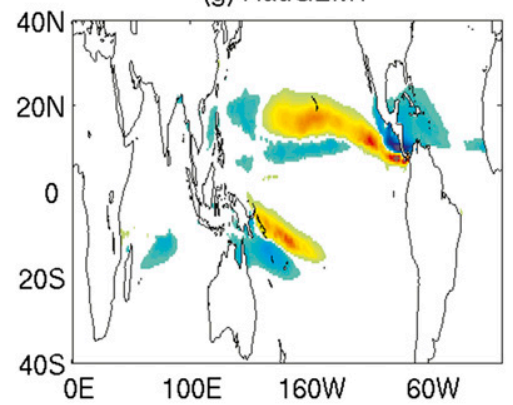

(b) CCCMA

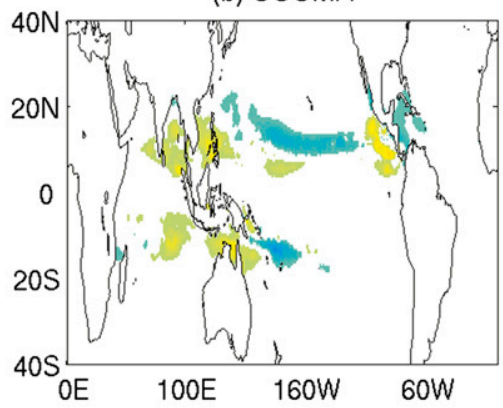

(e) GFDL20

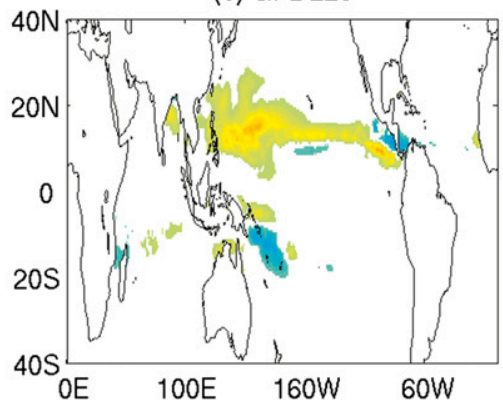

(h) MIROC

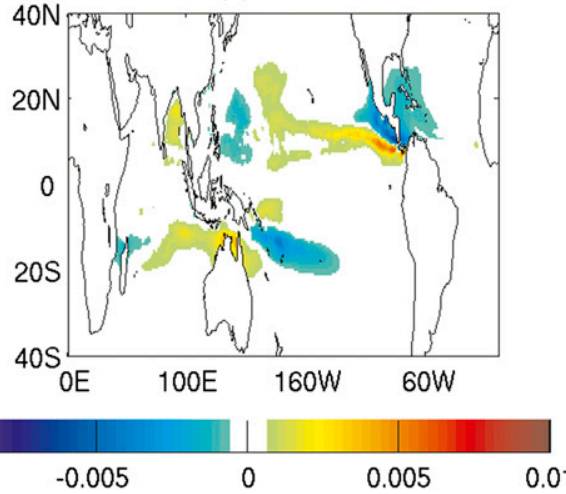

(c) Echam5

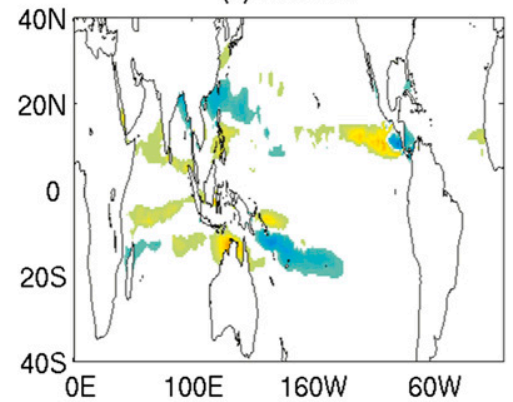

(f) $\mathrm{HadCM} 3$

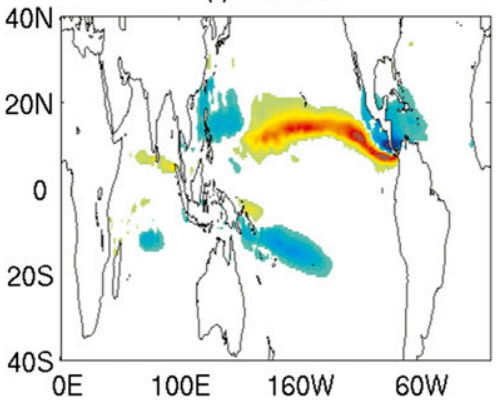

(i) MRI

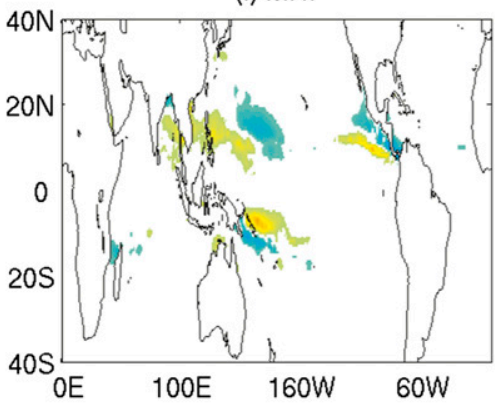

FIG. 7. Difference in the climatology of TCGI-R for the future simulations with different SST anomalies and the present control simulation, using the following as TCGI-R predictors: vorticity, vertical shear, column relative humidity, and RSST.

fidelity when forced with observed SST. The model is skillful in interannual hindcast mode (i.e., given the SST) in most basins, with the exception of the north Indian Ocean.

We will first examine the set of simulations with HiRAM forced by different specified SST fields. The same simulations were discussed in Zhao et al. (2009) and Zhao and Held (2012). Each SST field is a function of position and time of year but has no interannual or submonthly variability. The first simulation is a $25-\mathrm{yr}$ control run, in which the model is forced with the climatological SST from the Hadley Centre. For the future climate runs, the climatological SSTs are modified by the addition of SST anomalies from the CMIP3 simulations (Zhao and Held 2012).

The atmospheric $\mathrm{CO}_{2}$ concentration is also increased in the model to be consistent with the A1B scenario for the period 2081-2100, from which the SST anomalies were calculated. The anomalies were calculated as the differences between the multimodel ensemble mean 2081-2100 SSTs in the A1B scenario with the SSTs in the historical simulations in the period 2001-20 for the multimodel ensemble mean. The simulation forced with the SSTs anomalies from the multimodel ensemble mean is called "warm" here and lasts 20 years. The simulations with the individual model SST anomalies 
are named by the model and last 10 years each. The SST anomalies are calculated separately for each month and grid point and are discussed in Zhao and Held (2012).

The two final simulations, considered in a separate section, last 25 years each. In the first one, the SST is kept at the present climatological values, and only the $\mathrm{CO}_{2}$ in the model is doubled $\left(2 \times \mathrm{CO}_{2}\right)$. In the second one, a uniform warming of $2 \mathrm{~K}$ is added to the climatological SST, but $\mathrm{CO}_{2}$ is not increased; this is called the "plus $2 \mathrm{~K}$ " or " $\mathrm{p} 2 \mathrm{~K}$ " simulation. The response of HiRAM to an increase of $\mathrm{CO}_{2}$ with fixed SST and the comparison of that to the response in the $\mathrm{p} 2 \mathrm{~K}$ simulation was analyzed by Held and Zhao (2011). Table 1 summarizes the 12 simulations considered in this study.

The relative SST (RSST) is defined as the SST at each grid point minus the mean SST of the region $20^{\circ} \mathrm{S}-20^{\circ} \mathrm{N}$ (Vecchi and Soden 2007; Vecchi et al. 2008). The potential intensity (PI) was calculated using the algorithm developed by Kerry Emanuel and based on the procedure described in Emanuel (1995) and Bister and Emanuel $(1998,2002 a, b)$. The column relative humidity for HiRAM was calculated as the ratio of the monthly fields of columnintegrated water vapor $W$ and saturated water vapor $W *$ (i.e., $W / W_{*}$ ). The saturation deficit is defined as the difference of these quantities (i.e., $W-W_{*}$ ).

\section{Tropical cyclone activity in HiRAM}

The tropical cyclone activity in HiRAM has been discussed extensively in previous studies (Zhao et al. 2009, 2010; Zhao and Held 2010, 2012; Held and Zhao 2011). Here we give only a short summary of the results. The algorithm used to define and track model storms is based on Vitart et al. (1997, 2003) and Knutson et al. (2007) and described in detail in the appendix B of Zhao et al. (2009).

The first position density and the tracks in both observations and the control simulation with HiRAM are shown in Fig. 1. The model's first position density pattern is quite similar to the observed pattern. Biases are noticeable only in a few regions. For example, storms form in the model, unrealistically, near the Nordeste coast of Brazil. The genesis density in the central North Pacific is too high. The genesis rate of subtropical storms is greater than that in observations in the Southern Hemisphere.

The HiRAM tracks are also, overall, very similar to observed tracks. However, in some regions, the HiRAM tracks tend to be longer than the observed ones, especially in the Southern Hemisphere, the eastern North Pacific, and the Arabian Sea. The mean numbers of storms per month in both hemispheres and in a few individual basins in the HiRAM control run and in observations are shown in Fig. 2, with the basins definition given in Table 2. The seasonal cycle of the HiRAM

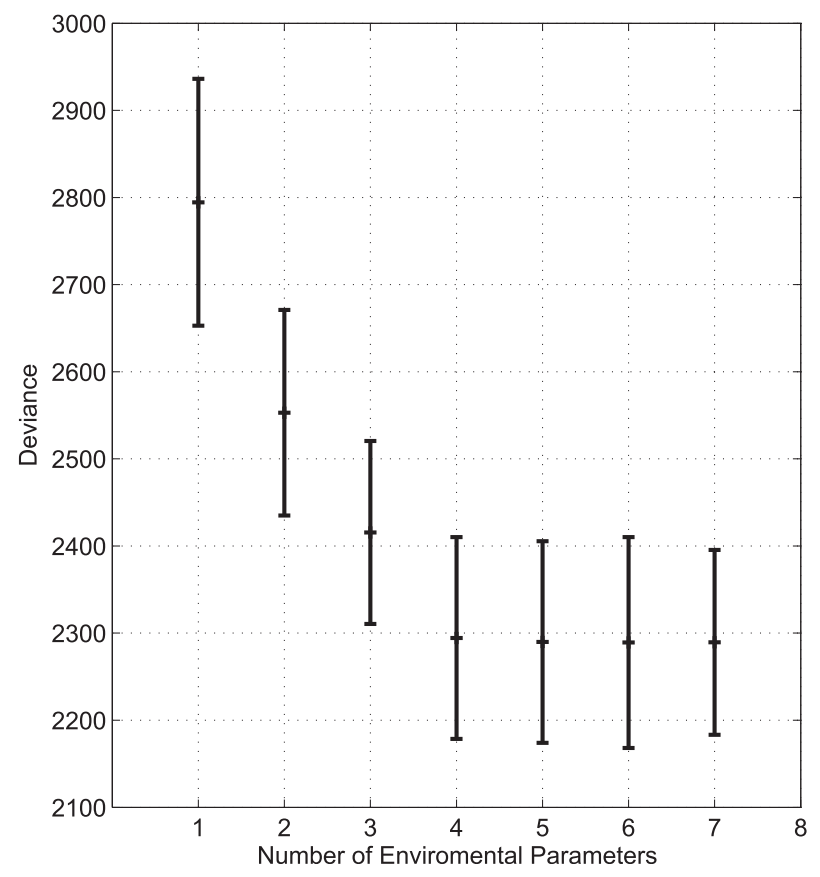

FIG. 8. Deviance as a function of the number of environmental parameters used in the Poisson regression. Error bars indicate the \pm standard deviation.

mean number of TCs (NTC) is very similar to the seasonal cycle derived from the observations in both hemispheres. However, in both hemispheres, the model produces too many TCs in the off-season. In the peak season of each hemisphere, the model NTC is very close to the observations but is slightly below the observed mean in August (Northern Hemisphere) and February (Southern Hemisphere). When we examine a few individual basins, there are regions in which the model performs better than in others. For instance, while the model has a tendency to produce too many TCs in the south Indian Ocean (Fig. 2c), the peak season in the Australian region (Fig. 2d) has too few TCs. The formation of storms in the off-season is more concentrated in the western North Pacific (Fig. 2e) than in the North Atlantic (Fig. 2f). Because of model resolution $(50 \mathrm{~km})$, HiRAM is not expected to be able to simulate the most intense TCs (categories 4 and 5), for which much higher resolution would be necessary [or additional downscaling could be used (e.g., Bender et al. 2010)].

In summary, as shown in many previous papers, HiRAM's TC activity in the present climate is close to observed with respect to the seasonal cycle, location, and shapes of the tracks. A multimodel comparison of the ability of the high-resolution climate models to simulate TC activity (Shaevitz et al. 2014) shows that HiRAM is one of the top models of the current generation of high-resolution climate models. This 
TABLE 3. Coefficients of the Poisson regression between TCGI-R (Tippett et al. 2011) and TCGI-H using various predictors. The humidity predictor can be the $\mathrm{CRH}$, the $\mathrm{RH}$ at $600 \mathrm{hPa}$, the $\mathrm{SD}$, the vertical velocity at $500 \mathrm{hPa}(\mathrm{VV})$, or the convective precipitation $(\mathrm{CP})$. The thermal predictor can be the SST, RSST, or PI. For the reanalysis case, only the coefficients for the CRH and RSST are shown. Note that the index procedure was modified for the VV and CP indices, with the monthly varying fields used in the Poisson regression, instead of climatological monthly fields (used for the CRH, RH, and SD TCGI-H indices, as well as the TCGI-R index).

\begin{tabular}{|c|c|c|c|c|c|c|c|}
\hline Index & Vorticity & Humidity & Thermal & Shear & Constant & $\mathrm{AIC} \times 10^{4}$ & $\sigma^{2} \times 10^{4}$ \\
\hline TCGI-R & 1.12 & 0.12 & 0.46 & -0.13 & -11.96 & 1.2213 & 0.0003 \\
\hline $\mathrm{CRH}$ and RSST & 1.20 & 0.10 & 0.40 & -0.12 & -14.34 & 2.8528 & 2.2833 \\
\hline $\mathrm{CRH}$ and SST & 1.24 & 0.10 & 0.42 & -0.12 & -26.02 & 2.8579 & 2.2883 \\
\hline $\mathrm{CRH}$ and PI & 1.41 & 0.12 & 0.08 & -0.13 & -21.18 & 2.8628 & 2.2983 \\
\hline RH and RSST & 1.18 & 0.05 & 0.35 & -0.12 & -10.32 & 2.8799 & 2.3154 \\
\hline RH and SST & 1.22 & 0.06 & 0.36 & -0.13 & -20.39 & 2.8759 & 2.3114 \\
\hline RH and PI & 1.38 & 0.06 & 0.08 & -0.13 & -16.01 & 2.8891 & 2.3246 \\
\hline SD and RSST & 1.21 & 0.13 & 0.57 & -0.13 & -4.61 & 2.8607 & 2.2962 \\
\hline SD and SST & 1.27 & 0.14 & 0.59 & -0.13 & -20.72 & 2.8530 & 2.2884 \\
\hline SD and PI & 1.45 & 0.13 & 0.11 & -0.14 & -12.14 & 2.9044 & 2.3399 \\
\hline VV and RSST & 1.96 & -0.12 & 0.39 & -0.11 & -11.17 & 93.992 & 92.543 \\
\hline VV and SST & 2.00 & -0.12 & 0.39 & -0.11 & -21.82 & 94.112 & 92.266 \\
\hline VV and PI & 2.09 & -0.12 & 0.06 & -0.12 & -15.26 & 95.511 & 93.367 \\
\hline $\mathrm{CP}$ and RSST & 2.09 & 0.15 & 0.36 & -0.10 & -12.21 & 92.700 & 91.253 \\
\hline CP and SST & 2.12 & 0.15 & 0.35 & -0.10 & -21.69 & 92.935 & 91.487 \\
\hline $\mathrm{CP}$ and PI & 2.17 & 0.15 & 0.05 & -0.11 & -15.58 & 93.997 & 92.549 \\
\hline
\end{tabular}

suggests that the model ought to be a good tool with which to examine frequency changes of TCs in various future scenarios.

Our main interest in this analysis is to determine to what extent the genesis indices are able to predict the differences between the future and present TC frequency. Knutson et al. (2010) have shown that high-resolution models agree on two main robust results regarding future TC activity: a slight reduction in the global frequency of TCs and a shift toward more intense storms. The magnitudes of these changes vary from one model to the next. The global reduction in frequency is a good test for a genesis index derived by fitting the spatial and seasonal variations in genesis. It should be noted, though, that a recent downscaling of the CMIP5 models led to an increase in the global TC frequency in the future (Emanuel 2013), in contrast to previous results using the same methodology (Emanuel et al. 2008) and other climate models.

Figure 3 shows the global number of TCs in the present and future cases forced with SST anomalies, while the differences in first-position climatology between future cases and the present are shown in Fig. 4. In all future simulations, there is a reduction of the number of TCs in the future (with different magnitudes), depending on the SST pattern. The SST anomalies are clearly correlated with the regions of increase and decrease of TC activity. ${ }^{1}$ This is the main issue we want to address here: how well can the TCGI (and other genesis indices) reproduce the

\footnotetext{
${ }^{1}$ The SST anomaly patterns of a few cases are shown in Fig. 12 of Zhao et al. (2009).
}

global reduction of TCs in the future runs while still capturing the spatial and seasonal structure of genesis in the control climate? We will use HiRAM's own TCs and environmental variables to examine this question in the next sections.

\section{TCGI-R applied to HiRAM}

As a first step in our analysis, we applied the TCGI developed using reanalysis fields (Tippett et al. 2011) to data from HiRAM. We calculated the values of the TCGI-R using the monthly output data of each simulation. The resulting TCGI-R fields for the control (forced with climatological SST) are shown together with those computed from the NCEP and ERA-40 reanalyses in Fig. 5. The climatology of HiRAM for the present is very similar to that of the reanalysis. The main differences are the higher values of the index in the eastern North Pacific and South Pacific and the shift in the location of the western North Pacific maximum northeastward, compared with the reanalysis climatology for the period 1961-2000.

Similarly, we calculated the climatologies for the future scenarios forced with SST anomalies. These are shown in Fig. 6. As might have been expected, the gross features of the climatologies are very similar, with differences in the maxima's locations and strengths in each case varying according to the SST anomaly patterns in each case. The main differences in the patterns of TCGI-R in the various future scenarios occur in their magnitude in the Pacific Ocean, in particular the eastern and central North Pacific and the South Pacific.

Next, we compare the future climatologies of TCGI-R with that in the present in the HiRAM simulations. The 
(a) Warm

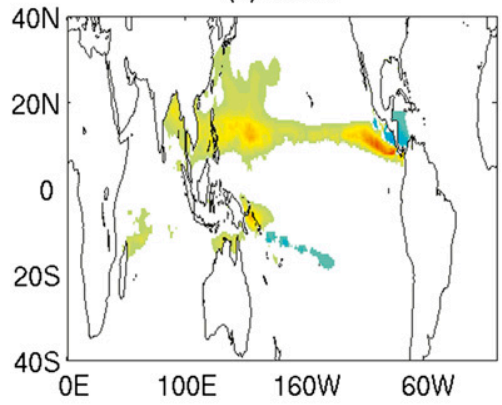

(d) GFDL21

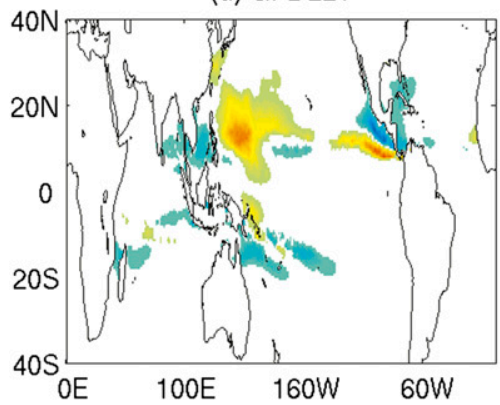

(g) HadGEM1

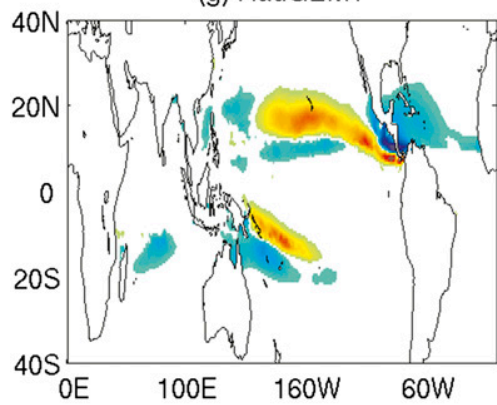

(b) CCCMA

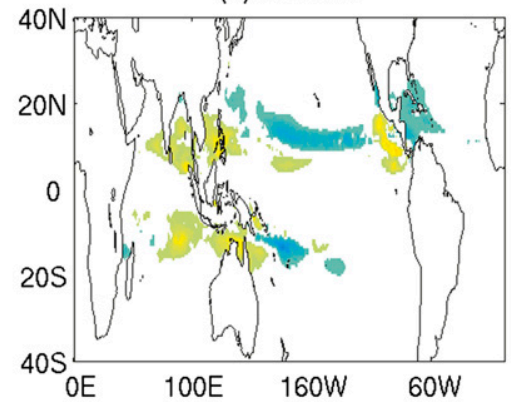

(e) GFDL20

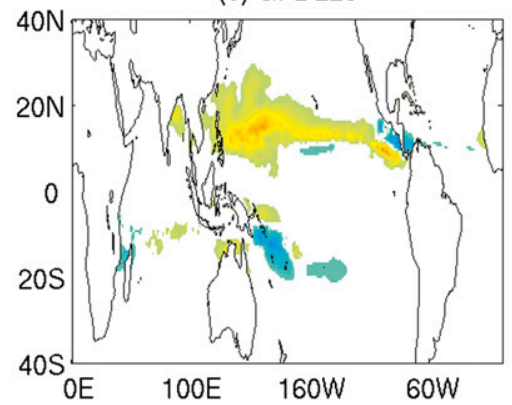

(h) MIROC

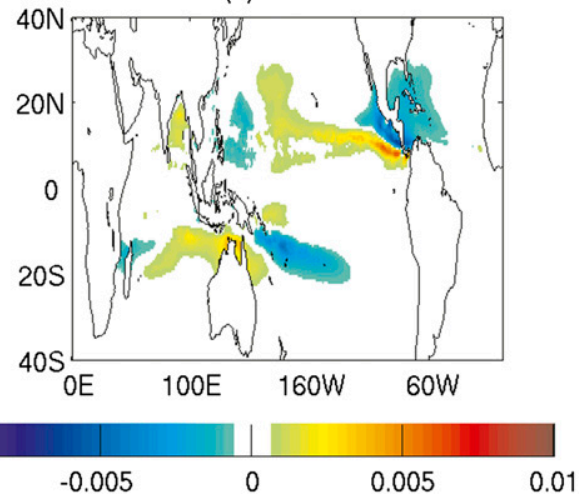

0.01 (c) Echam5

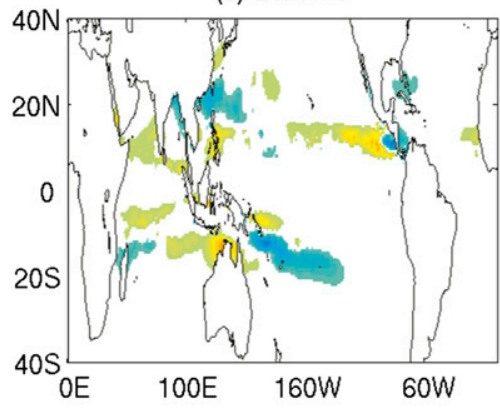

(f) $\mathrm{HadCM} 3$

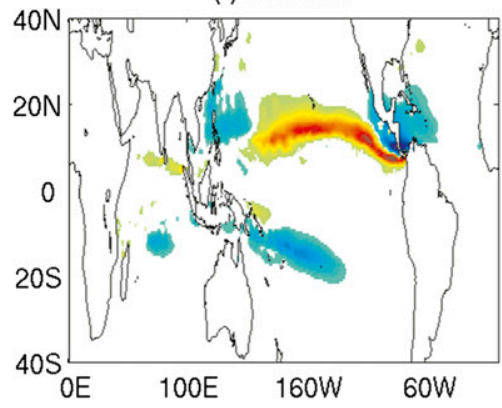

(i) MRI

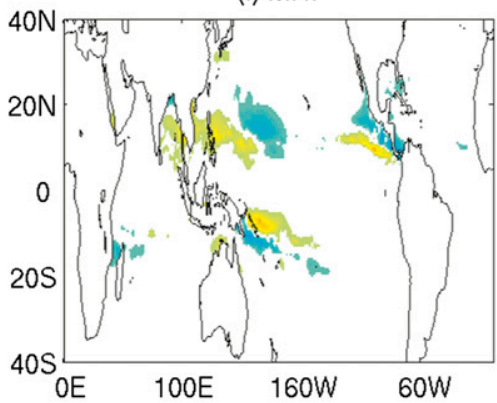

$-0.01$

FIG. 9. Difference in the climatology of TCGI-H for the future simulations with different SST anomalies and the present control simulation, using the following as TCGI-H predictors: vorticity, vertical shear, column relative humidity, and RSST.

differences between them are shown in Fig. 7. The largest differences occur in the North Pacific, with the index having large increases in that region in many future runs, in particular the Hadley Centre Coupled Model, version 3 (HadCM3). While the number of TCs in all future scenarios decreases globally compared with the present, the difference in TCGI-R is positive when integrated globally, indicating that the index predicts an increase in the number of TCs (see Table 5). The TCGI$\mathrm{R}$ index fails to predict the reduction in the number of TCs observed in HiRAM, as shown by the fractional change of the mean number of TCs and index-predicted number of tropical cyclones (INTC, defined as the integrated value of the TCGI) using TCGI-R in future scenarios compared with the present climate (shown in Table 5). In the present climate, the root-mean-square error (RMSE) of the global INTC by year obtained using the TCGI-R is actually larger than in most future scenarios (as shown in Table 6). Furthermore, RMSE of the difference $(\Delta)$ and fractional change (FC) between present and future scenarios between global mean NTC and INTC predicted by TCGI-R are also large (as shown in Table 7).

\section{TCGI obtained from HiRAM}

One possible reason for the TCGI-R to increase in the future while the NTC decreases in the same simulations could be that the index was obtained using a statistical 
regression between reanalysis variables and observed TCs, instead of using the model output itself to derive the index. Therefore, we repeat the TCGI fitting procedure using the HiRAM simulations of present-day climate fields and HiRAM TCs. Besides the variables used in the TCGI-R, we test various other variable combinations for our predictands. We will call the indices obtained from HiRAM data TCGI-H and will test their abilities to predict the global number of future TCs in the model.

First, we determine the optimal number of parameters for the TCGI-H index. We consider the same group of variables used in Tippett et al. (2011) [i.e., clipped vorticity, vertical shear, column relative humidity (CRH), relative humidity at $600 \mathrm{hPa}(\mathrm{RH})$, sea surface temperature, relative sea surface temperature, and potential intensity]. We also consider one additional variable, saturation deficit (SD), which is similar to the variable that was used in Emanuel (2010): entropy saturation deficit. Figure 8 shows the deviance computed using the HiRAM fields for the present climate. Our procedure is the same described in Tippett et al. (2012). It is a forward selection procedure in which one variable is added at a time, and the variable whose addition most reduces the deviance is identified. The deviance is calculated using cross validation, with the data randomly separated in 10 subsets, 9 of which are used to estimate the regression coefficients, and 1 is used to calculate the deviance, leading to 10 estimates of the deviance to each partition of the data. Here we use 10 partitions and obtain 100 estimates of the deviance. The mean and standard deviation of the deviance as a function of the number of environmental parameters are shown in Fig. 8. There are significant decreases in deviance as the number of the environmental parameters increases from one to four, but further increases in the number of parameters do not result in significant decreases in deviance.

The four environmental parameters chosen as described above are exactly the same as those obtained using the reanalysis and observed TC data to derive the TCGI-R [i.e., low-level vorticity, vertical wind shear, column relative humidity, and RSST]. As a consequence, we obtained a new index, TCGI-H, with the same variables but slightly different coefficients than TCGI-R. The coefficients of TCGI-R and TCGI-H are compared in Table 3. Note that the large difference in the constant coefficient is due to the difference in horizontal resolution between HiRAM and the reanalysis. The coefficients, the deviance, and the Akaike information criteria (AIC) for this and various other four-parameter indices are given in Table $3{ }^{2}$

\footnotetext{
${ }^{2}$ The vertical velocity and convection precipitation TCGI-H indices will be discussed later.
}

TABLE 4. Deviance based $R$-squared (Cameron and Windmeijer 1996) for the 9 top TCGI-H defined in Table 3. The humidity predictor can be the $\mathrm{CRH}$, the $\mathrm{RH}$ at $600 \mathrm{hPa}$, or the SD. The thermal predictor can be the SST, RSST, or PI. The forward selection procedure picked the order of the predictors as thermal, clipped vorticity, humidity, and vertical shear for all cases. When calculating the deviance based $R$-squared, we added one predictor at a time in this order.

\begin{tabular}{lcccc}
\hline \hline \multicolumn{1}{c}{ Index } & Thermal & Vorticity & Humidity & Shear \\
\hline CRH and RSST & 0.191 & 0.261 & 0.301 & 0.336 \\
CRH and SST & 0.185 & 0.259 & 0.303 & 0.337 \\
CRH and PI & 0.149 & 0.230 & 0.297 & 0.334 \\
RH and RSST & 0.191 & 0.261 & 0.292 & 0.329 \\
RH and SST & 0.185 & 0.259 & 0.294 & 0.330 \\
RH and PI & 0.149 & 0.230 & 0.288 & 0.327 \\
SD and RSST & 0.191 & 0.261 & 0.298 & 0.335 \\
SD and SST & 0.185 & 0.259 & 0.301 & 0.337 \\
SD and PI & 0.149 & 0.230 & 0.277 & 0.322 \\
\hline
\end{tabular}

We then used the HiRAM environmental variables to calculate the values of the "best" TCGI-H index in the present-climate and warm scenarios. The climatological patterns are very similar to those shown in Figs. 5a and 6 and are not shown. The difference in the future scenarios and the present climate of the TCGI-H index is shown in Fig. 9. Similarly to what we obtained when using TCGI-R, TCGI-H leads to an increase in TC activity in HiRAM, while there is a decrease in the mean global NTC, and the largest increases in the index occurred in the North Pacific.

Given that our first choice of predictors did not lead to the reduction of TC activity in the model, we tested various other combinations of four predictors, as shown in Table 3. In each case, we examined the ability of the resulting index to simulate a reduction in global TC frequency in the future, as well as the AIC in the present climate. Similarly to Tippett et al. (2011, 2012), we used a forward selection procedure in which one variable is added at a time to each of these genesis indices, and the variable whose addition most reduces the deviance is identified. For the prediction combinations obtained for monthly climatology (top 9 TCGI-H indices in Table 3), the same order of predictors was obtained in all cases: namely, thermodynamical variable, clipped vorticity, humidity variable, and vertical shear. To determine how much of the deviance each of the predictors can explain, we added one predictor at a time to the index in this order and calculated the deviance $R$-squared (Cameron and Windmeijer 1996). The results are given in Table 4, showing that the predictor that explains most of the deviance is the thermodynamical variable in all cases.

The mean number global of genesis events for all versions of the TCGI-H, as well as the fractional change in INTC in future scenarios, is also given in Table 5. In 
TABLE 5. NTC globally in each of the HiRAM simulations and the FC in NTC, defined as the difference of the mean NTC in climatology and in the future runs divided by the mean NTC in the climatology, are shown. INTC predicted using the reanalysis index TCGI-R and various versions of the HiRAM index TCGI-H (with different predictors), as well as the INTC FC in each scenario are labeled according to the two predictors that vary in each TCGI-H case. The global distributions of NTC in all future scenarios are significantly different than the distribution of the global NTC in the present climate using a $t$ test ( $99 \%$ significance level) and are marked in bold face. If the distribution of number of the global INTC in future and present climates are statistically distinct using a $t$ test, the future INTC values are shown in bold face. In the case of convection precipitation and vertical velocity, we used the median of the distributions instead of the mean.

\begin{tabular}{|c|c|c|c|c|c|c|c|c|c|c|c|c|}
\hline & $\mathrm{CL}$ & $\mathrm{W}$ & WC & WE & WG & W0 & W3 & W1 & WO & WI & $2 \times \mathrm{CO}_{2}$ & $\mathrm{P} 2 \mathrm{~K}$ \\
\hline \multirow[t]{2}{*}{ HiRAM } & 114.3 & 85 & 80.9 & 82.6 & 87.8 & 93.8 & 95.4 & 84.9 & 91.1 & 85.4 & 101.8 & 101.9 \\
\hline & $\mathrm{FC}$ & -0.26 & -0.29 & -0.28 & -0.23 & -0.18 & -0.16 & -0.26 & -0.20 & -0.25 & -0.11 & -0.11 \\
\hline \multirow[t]{2}{*}{ TCGI-R } & 65.0 & 81.1 & 64.9 & 67.4 & 68.6 & 72.3 & 71.1 & 67.4 & 65.1 & 65.0 & 270.1 & 20.1 \\
\hline & $\mathrm{FC}$ & 0.25 & 0 & 0.04 & 0.06 & 0.11 & 0.09 & 0.04 & 0 & 0 & 3.17 & -0.69 \\
\hline \multirow[t]{2}{*}{$\mathrm{CRH}$ and RSST } & 124.0 & 148.1 & 123.3 & 127.7 & 128.0 & 136.2 & 132.7 & 126.3 & 123.5 & 123.3 & 399.0 & 46.9 \\
\hline & FC & 0.19 & -0.01 & 0.03 & 0.03 & 0.10 & 0.07 & 0.02 & 0 & -0.01 & 2.22 & -0.62 \\
\hline \multirow[t]{2}{*}{$\mathrm{CRH}$ and SST } & 104.6 & 262.2 & 230.8 & 307.1 & 221.9 & 251.6 & 231.1 & 256.1 & 346.0 & 205.7 & 335.8 & 91.6 \\
\hline & $\mathrm{FC}$ & 1.51 & 1.21 & 1.94 & 1.12 & 1.41 & 1.21 & 1.44 & 2.31 & 0.97 & 2.21 & -0.12 \\
\hline \multirow[t]{2}{*}{$\mathrm{CRH}$ and PI } & 134.5 & 182.7 & 155.8 & 167.7 & 152.0 & 163.1 & 157.2 & 162.7 & 168.3 & 147.9 & 27.4 & 56.1 \\
\hline & $\mathrm{FC}$ & 0.36 & 0.16 & 0.25 & 0.13 & 0.21 & 0.17 & 0.21 & 0.25 & 0.10 & 2.92 & -0.58 \\
\hline \multirow[t]{2}{*}{ SD and RSST } & 142.6 & 117.4 & 86.7 & 74.8 & 91.9 & 95.0 & 95.4 & 83.1 & 65.7 & 92.6 & 22.2 & 29.4 \\
\hline & $\mathrm{FC}$ & -0.18 & -0.39 & -0.47 & -0.36 & -0.33 & -0.33 & -0.42 & -0.54 & -0.35 & 1.96 & -0.79 \\
\hline \multirow[t]{2}{*}{ SD and SST } & 121.2 & 277.8 & 219.0 & 262.6 & 206.9 & 233.2 & 217.0 & 231.8 & 285.5 & 198.3 & 390.6 & 71.6 \\
\hline & $\mathrm{FC}$ & 1.29 & 0.81 & 1.17 & 0.71 & 0.92 & 0.79 & 0.91 & 1.36 & 0.64 & 2.22 & -0.41 \\
\hline \multirow[t]{2}{*}{ SD and PI } & 144.7 & 133.5 & 107.3 & 98.6 & 107.0 & 109.4 & 110.4 & 105.8 & 90.3 & 106.6 & 89.4 & 44.9 \\
\hline & $\mathrm{FC}$ & -0.08 & -0.26 & -0.32 & -0.26 & -0.24 & -0.24 & -0.27 & -0.38 & -0.26 & 1.69 & -0.69 \\
\hline \multirow[t]{2}{*}{ VV and RSST } & 114 & 106 & 110 & 99.5 & 114 & 113.5 & 130.5 & 125.5 & 112.5 & 105.5 & 103 & 106 \\
\hline & $\mathrm{FC}$ & -0.07 & -0.03 & -0.13 & 0 & 0 & 0.14 & 0.10 & -0.01 & -0.07 & -0.10 & -0.07 \\
\hline \multirow[t]{2}{*}{ VV and SST } & 119 & 218 & 239 & 269 & 229 & 241 & 267 & 296 & 357 & 207.5 & 106 & 240 \\
\hline & FC & 0.83 & 1.01 & 1.26 & 0.92 & 1.03 & 1.24 & 1.49 & 2.00 & 0.74 & & 1.01 \\
\hline \multirow[t]{2}{*}{ VV and PI } & 99 & 100 & 109 & 103.5 & 106.5 & 105 & 121.5 & 126 & 119.5 & 99 & 84 & 111 \\
\hline & FC & 0.01 & 0.10 & 0.04 & 0.08 & 0.06 & 0.23 & 0.27 & 0.21 & 0 & -0. & 0.12 \\
\hline \multirow[t]{2}{*}{ CP and RSST } & 108 & 127.5 & 123 & 146.5 & 134 & 122 & 170 & 141 & 151 & 117 & 105 & 115 \\
\hline & FC & 0.18 & 0.14 & 0.36 & 0.24 & 0.13 & 0.57 & 0.31 & 0.40 & 0.08 & -0.03 & 0.06 \\
\hline \multirow[t]{2}{*}{$\mathrm{CP}$ and SST } & 118 & 258.5 & 257.5 & 377.5 & 264 & 253.5 & 341.5 & 313 & 439.5 & 222 & 115 & 250 \\
\hline & $\mathrm{FC}$ & 1.19 & 1.18 & 2.20 & 1.24 & 1.14 & 1.89 & 1.65 & 2.72 & 0.88 & -0.02 & 1.12 \\
\hline \multirow[t]{2}{*}{$\mathrm{CP}$ and PI } & 84 & 106 & 106 & 128.5 & 108.5 & 101.5 & 136 & 122.5 & 142 & 95.5 & 78 & 106 \\
\hline & FC & 0.26 & 0.26 & 0.53 & 0.29 & 0.21 & 0.62 & 0.46 & 0.69 & 0.14 & -0.07 & 0.26 \\
\hline
\end{tabular}

Table 6 we show the root-mean-square error of the INTC for TCGI-R and the various TCGI-H indices. Furthermore, in Table 7 the RMSE of the mean INTC changes and fractional changes for all indices are shown. All indices with the column relative humidity predict an increase in TC activity in the future of varying magnitude depending on which thermodynamic variable is considered (SST, RSST, or PI).

Emanuel (2010) pointed out the importance of using the entropy saturation deficit in predicting future tropical cyclone activity. When the saturation deficit is used as one of the index predictors (Fig. 10, right panels), we obtain a reduction in future cyclone frequency, if the saturation deficit is used in conjunction with either PI or RSST (see Table 5). We also show in Fig. 10 the difference of the mean global NTC in the present and the mean global NTC in the future scenarios (white bars) for the 3 TCGI-H indices with the saturation deficit. While the combination of both PI and RSST with saturation deficit results in a reduction of the index, amounting to a prediction of a decrease of TC activity in the future, the magnitude of the decrease is higher than that which occurs in the model-simulated NTC when RSST is one of the predictors. On the other hand, the fractional decrease in the index constructed using the combination of saturation deficit and PI is very close to the model fractional decrease in NTC, as can be confirmed by comparing the fractional changes (Table 5) and RMSE values of INTC with NTC (Table 6) and their fractional changes (Table 7).

Using the change in the global tropical cyclone frequency in future and present as our measure for the best TCGI-H index, the pairing of saturation deficit and PI seems to be the best choice of those we tried. These predictors are very similar to those Emanuel (2010) used in his improved genesis potential index, although the methodologies by which the two were derived are very different. However, if we apply the Emanuel (2010) 
TABLE 6. RMSE between the global NTC per year in each of the HiRAM simulations and global INTC per year predicted using the reanalysis index TCGI-R and various versions of the HiRAM index TCGI-H (with different predictors).

\begin{tabular}{|c|c|c|c|c|c|c|c|c|c|c|c|c|}
\hline & $\mathrm{CL}$ & $\mathrm{W}$ & $\mathrm{WC}$ & WE & WG & W0 & W3 & W1 & WO & WI & $2 \times \mathrm{CO}_{2}$ & $\mathrm{p} 2 \mathrm{~K}$ \\
\hline TCGI-R & 50.2 & 10.4 & 17.1 & 17.3 & 20.8 & 22.4 & 25.6 & 19.5 & 26.8 & 22.8 & 170.0 & 82.4 \\
\hline CRH and RSST & 13.0 & 64.0 & 42.5 & 45.9 & 40.9 & 43.0 & 38.1 & 42.2 & 33.1 & 39.4 & 298.1 & 55.9 \\
\hline $\mathrm{CRH}$ and SST & 12.9 & 177.6 & 150.0 & 224.7 & 134.3 & 158.1 & 136.0 & 171.4 & 255.0 & 120.8 & 234.8 & 14.7 \\
\hline CRH and PI & 22.5 & 98.5 & 75.2 & 85.8 & 64.8 & 69.7 & 62.5 & 78.5 & 77.5 & 63.5 & 426.7 & 47.0 \\
\hline SD and RSST & 29.7 & 33.9 & 8.2 & 11.5 & 9.1 & 6.8 & 7.9 & 8.6 & 26.2 & 12.8 & 321.5 & 73.1 \\
\hline SD and SST & 11.0 & 139.2 & 138.2 & 180.3 & 119.4 & 139.7 & 121.9 & 147.2 & 194.6 & 113.5 & 289.7 & 31.9 \\
\hline SD and PI & 32.4 & 50.0 & 27.5 & 19.2 & 21.3 & 16.9 & 17.6 & 23.3 & 6.54 & 23.8 & 288.6 & 58.0 \\
\hline VV and RSST & 9.0 & 29.4 & 29.6 & 18.4 & 27.9 & 27.7 & 42.8 & 44.4 & 22.7 & 22.2 & 9.7 & 15.5 \\
\hline VV and SST & 11.7 & 114.9 & 158.8 & 183.9 & 141.7 & 158.9 & 188.4 & 215.5 & 266.2 & 123.5 & 10.0 & 145.3 \\
\hline VV and PI & 16.2 & 25.7 & 29.1 & 22.3 & 20.9 & 15.8 & 38.3 & 44.2 & 29.3 & 16.8 & 20.2 & 20.4 \\
\hline $\mathrm{CP}$ and RSST & 11.9 & 181.7 & 48.9 & 111.6 & 69.1 & 29.5 & 103.7 & 58.0 & 67.9 & 34.1 & 11.2 & 117.9 \\
\hline $\mathrm{CP}$ and SST & 15.4 & 416.9 & 191.9 & 437.9 & 215.1 & 159.2 & 313.1 & 229.2 & 379.8 & 140.2 & 17.7 & 371.8 \\
\hline $\mathrm{CP}$ and PI & 29.4 & 152.6 & 32.3 & 100.0 & 39.1 & 10.0 & 80.4 & 39.5 & 59.6 & 17.6 & 24.9 & 110.4 \\
\hline
\end{tabular}

index to the HiRAM environmental variables, it predicts an increase in the TC activity in all scenarios (not shown), similar to what happens when using the Emanuel and Nolan (2004) original GPI (not shown). Although the predictors are very similar, the weights (or coefficients) given to each variable in each index are different. As shown here, small changes in the coefficients can lead to different predictions by the various indices. This is particularly true for the global mean changes, which contain much cancellation from larger (percentagewise) changes in individual basins.

Given that the combination of saturation deficit and PI gives the best results for the global mean change in HiRAM, we examine the spatial pattern of the climatology of this index in all the simulations (Fig. 11), as well as the differences between the future and present TCGI-H for that combination of variables (Fig. 12). The magnitude of this TCGI-H index in the present climate is significantly higher overall than that of the TCGI-R (Fig. 5a) but especially in the eastern North Pacific and the South Pacific.

While the decrease in TC activity in the future is apparent in all cases in Fig. 12, the Southern Hemisphere, particularly the South Pacific, is the location with the highest negative anomalies. Figure 13 is designed to examine whether the reduction in the frequency of storms in the model is similarly greater in the Southern Hemisphere compared with the Northern Hemisphere. Figure 13 shows the NTC per year in each hemisphere in future scenarios normalized by the mean NTC per year in the control run in each hemisphere. While there is a percentage reduction overall in both Northern and Southern Hemispheres, in most scenarios the reduction is larger in the Southern than the Northern Hemisphere. Furthermore, the only case in which there is a significant increase in the distribution of the percentage NTC in the future occurs in the Northern Hemisphere (HadCM3
SST). However, the interhemispheric asymmetry seems to be larger in the index than in the simulated NTC.

\section{a. Vertical velocity and convective precipitation}

Held and Zhao (2011) argued that changes in genesis in HiRAM in different future scenarios followed changes in the mean vertical motion, reflecting changes in convective mass fluxes. Zhao and Held (2012) analyzed the changes in the frequency of TC formation in the same HiRAM simulations that we analyze here. They computed correlations between different environmental variables individually and percentile changes in TC frequency. The variable with the highest correlation to TC

TABLE 7. RMSE between the difference in mean NTC in each of the HiRAM simulations in future and present climates $(\Delta \mathrm{NTC})$ and the mean or median (for vertical velocity and convective precipitation cases) difference of INTC in present and future scenarios $(\triangle I N T C)$ predicted using the reanalysis index TCGI-R and various versions of the HiRAM index TCGI-H (with different predictors) are shown in the first and third columns. The RMSE of the fractional change of NTC between the HiRAM simulations and the fractional changes in INTC are shown in the second and fourth columns. In the two first columns, the RMSE is calculated using only the warm scenarios, while the two last columns (All) also include the $2 \times \mathrm{CO}_{2}$ and $\mathrm{p} 2 \mathrm{~K}$ scenarios.

\begin{tabular}{lrcrc}
\hline \multicolumn{1}{c}{ Index } & \multicolumn{1}{c}{$\Delta \mathrm{W}$} & FC W & $\Delta$ All & FC All \\
\hline TCGI-R & 31.7 & 0.31 & 72.5 & 1.04 \\
CRH and RSST & 33.7 & 0.29 & 94.0 & 0.76 \\
CRH and SST & 184.1 & 1.74 & 182.0 & 1.72 \\
CRH and PI & 55.4 & 0.45 & 133.6 & 1.01 \\
SD and RSST & 30.1 & 0.17 & 97.1 & 0.68 \\
SD and SST & 145.7 & 1.22 & 157.3 & 1.31 \\
SD and PI & 15.9 & 0.09 & 83.2 & 0.58 \\
VV and RSST & 26.4 & 0.23 & 23.4 & 0.21 \\
VV and SST & 172.2 & 1.45 & 161.1 & 1.36 \\
VV and PI & 38.2 & 0.36 & 35.5 & 0.33 \\
CP and RSST & 68.9 & 0.52 & 63.7 & 0.47 \\
CP and SST & 256.2 & 1.89 & 240.5 & 1.75 \\
CP and PI & 72.2 & 0.64 & 67.5 & 0.59 \\
\hline
\end{tabular}


(a) Column RH \& PI

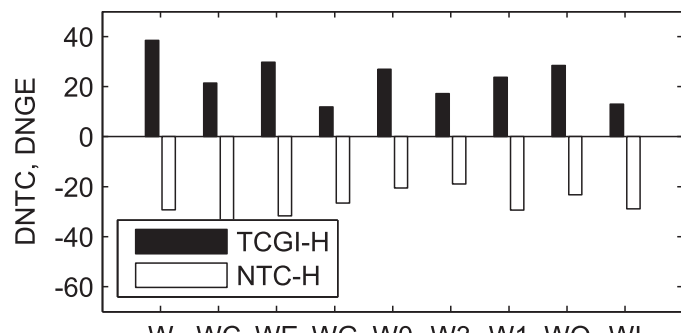

W WC WE WG WO W3 W1 WO WI

(c) Column RH \& RSST

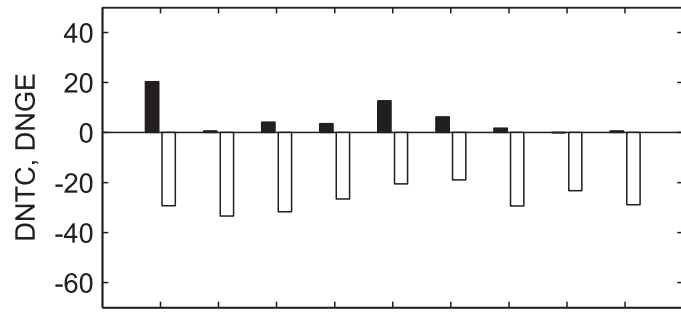

W WC WE WG WO W3 W1 WO WI

(e) Column RH \& SST

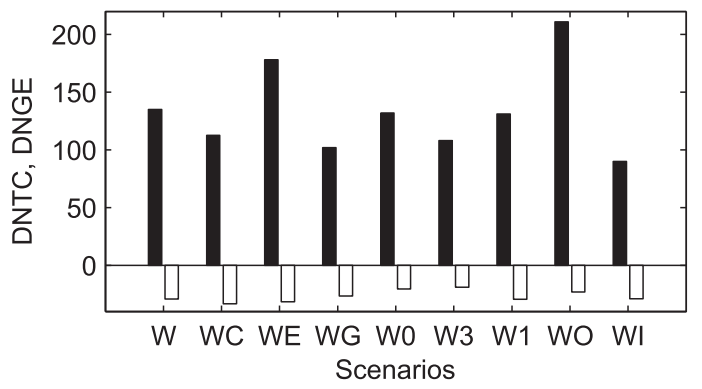

(b) Saturation Deficit \& PI

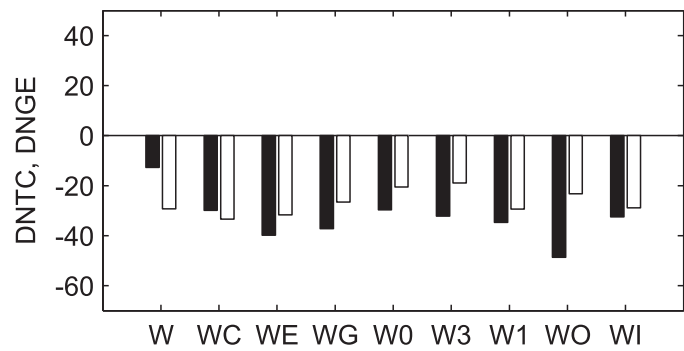

(d) Saturation Deficit \& RSST

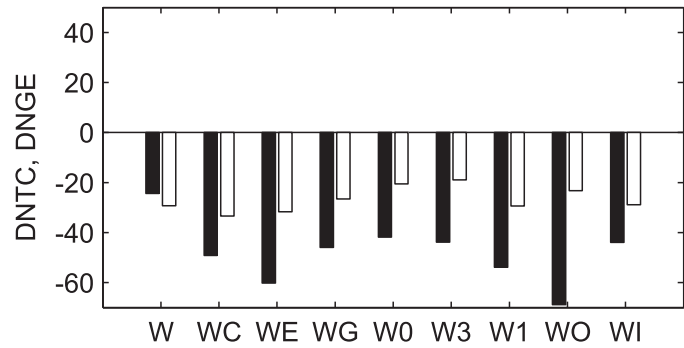

(f) Saturation Deficit \& SST

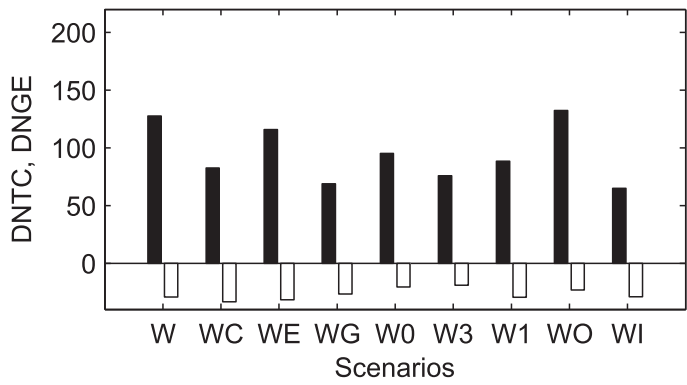

FIG. 10. Difference of globally integrated indices, ( $\triangle$ INTC in black bars) in the future (all warm scenarios) and the control simulation, using as predictors low-level vorticity, vertical wind shear, and either (left) column relative humidity or (right) saturation deficit, as well as (top) PI, (middle) RSST, or (bottom) SST. Difference of mean global NTC in future scenarios and present climatology for HiRAM ( $\triangle$ NTC in white bars).

frequency in their analysis, globally and by basin, was the 500-hPa pressure vertical velocity. This suggests that we should consider using $500-\mathrm{hPa}$ pressure vertical velocity as a possible predictor for the index. Another predictor that was used in other TC genesis indices was the convective precipitation (e.g., Royer et al. 1998). We test here whether including 500 -hPa vertical velocity or the convective precipitation as one of our predictors allows us to obtain a better relationship between the changes in the index and the changes in NTC in HiRAM in present and future climates.

The first step was to test if, using either vertical velocity or convective precipitation, we still have the same optimal number of predictors (four) that we obtained previously. This was indeed the case (not shown), and we obtained plots of the number of predictors very similar to that in Fig. 8 when including either climatological vertical velocity or convective precipitation in our analysis. Therefore, even though the vertical velocity by itself is a good predictor for changes in TC frequency changes, as shown in Zhao and Held (2012), it is necessary to use four predictors in deriving TCGI-H. As an additional test, we derived TCGI-H indices using only three predictors: vorticity, vertical shear, and one of the following: vertical velocity, column relative humidity, saturation deficit, or $600-\mathrm{hPa}$ relative humidity (i.e., SST, PI or RSST were not included). Analyzing the resulting climatologies of these indices (not shown), we can see that when one of the thermodynamical predictors (SST, RSST, or PI) is omitted, it is not possible to reproduce the climatological pattern of the TC activity globally. Thus, if we wish to have an index that is able to reproduce both the spatial and seasonal patterns of TC activity in the present, as well as to predict changes in future TC activity, four predictors are indeed necessary, confirming the results of our deviance analysis. 
(a) Clim

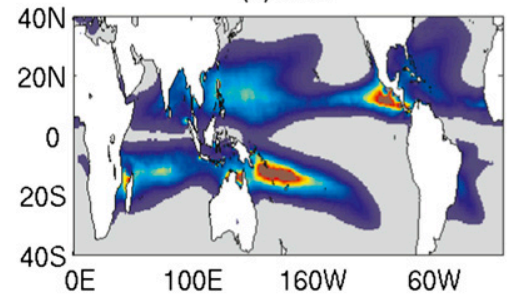

(d) Echam5

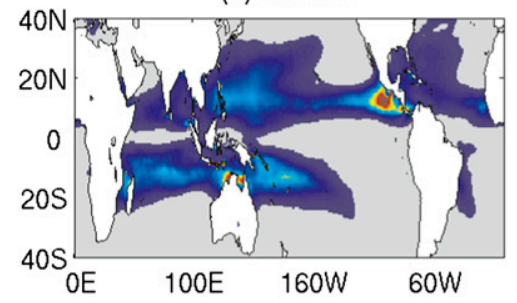

(g) $\mathrm{HadCM} 3$

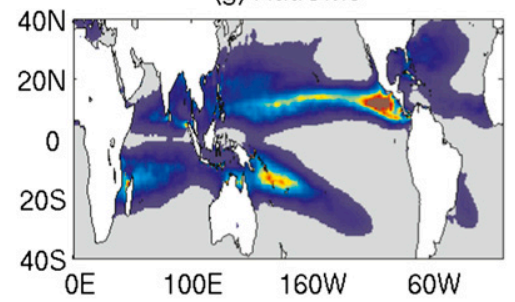

(j) MRI

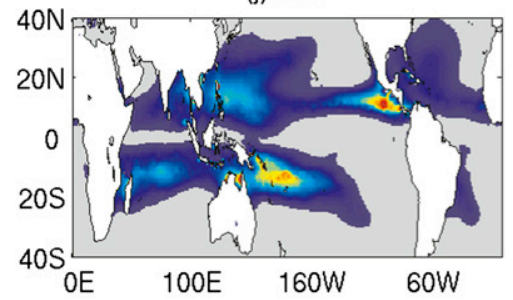

(b) Warm

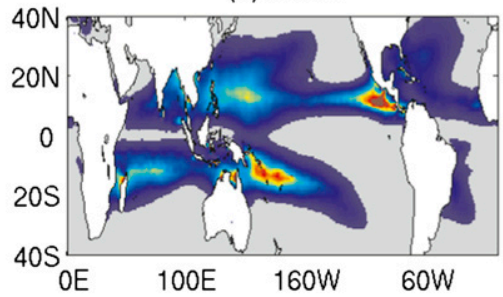

(e) GFDL21

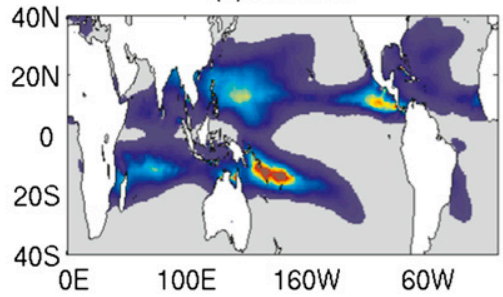

(h) HadGEM1

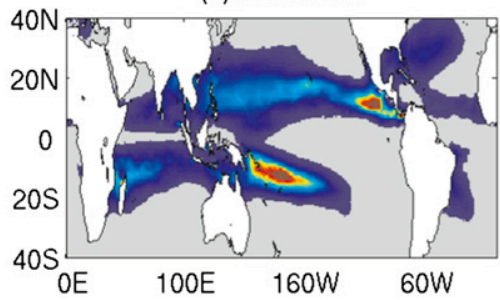

(k) $\mathrm{CO} 2$

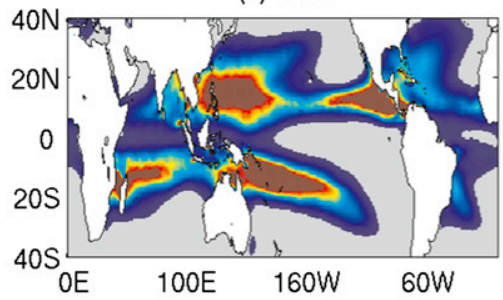

(c) CCCMA

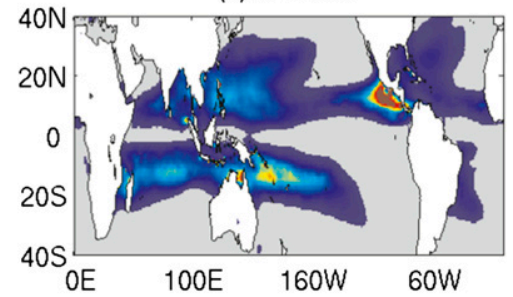

(f) GFDL20

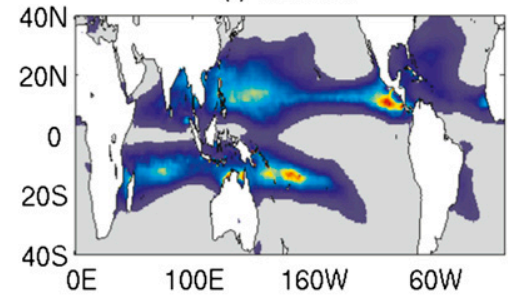

(i) MIROC

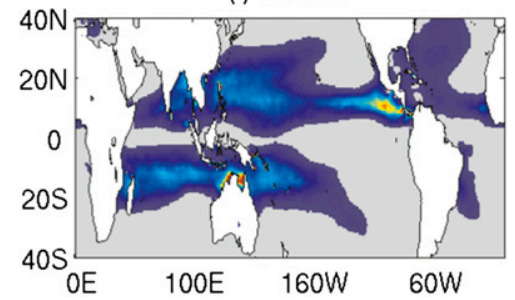

(I) $\mathrm{p} 2 \mathrm{~K}$

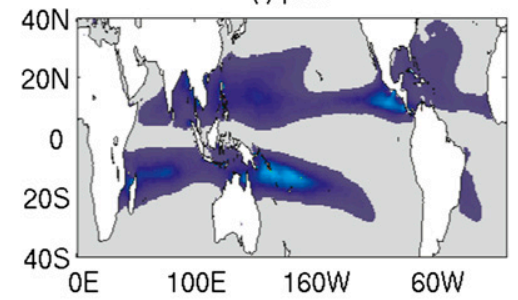

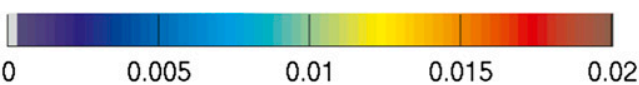

FIG. 11. Climatology of TCGI-H using as predictors vorticity, vertical shear, saturation deficit, and potential for the HiRAM present climatology and different future runs, as described in Table 1.

In our second step, we used as dynamical predictors the climatological values of low-level vorticity and vertical shear, but instead of either column relative humidity or saturation deficit (used above), we considered either the vertical velocity or the convective precipitation. In conjunction with these three predictors, we included the RSST, PI, or SST as the fourth possible predictor. While the climatological patterns of the vertical velocity and the convective precipitation are smooth fields, their monthly values are quite noisy, much more so than the humidity variables used previously. As a consequence, when we used the coefficients obtained using the Poisson regression from the climatological fields to calculate monthly varying indices, the resulting indices had very large-amplitude spatial and temporal variability. The global and 25-yr means of these integrated indices calculated with monthly varying fields were very different from that obtained from the climatological fields (i.e., with the parameters time averaged first, before computation of the index). The magnitudes of the coefficients for the index obtained using climatological means of either convective precipitation or vertical velocity are apparently too large when those indices are subsequently computed from monthly varying fields. Our solution for this problem was to use a different procedure for the Poisson regressions when considering either the convective precipitation or the vertical velocity as one of the 
(a) Warm

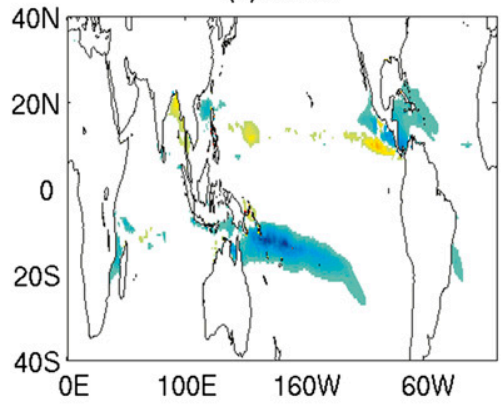

(d) GFDL

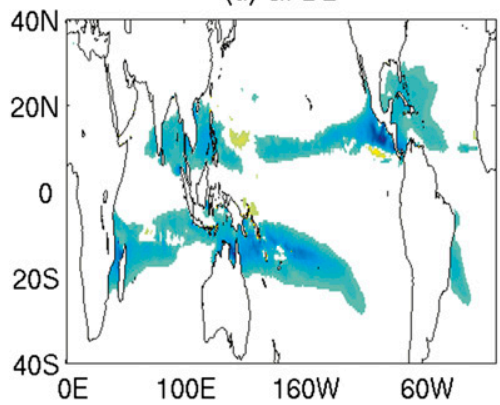

(g) HadGEM1

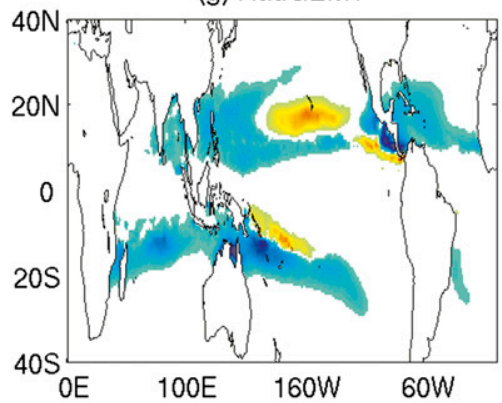

(b) CCCMA

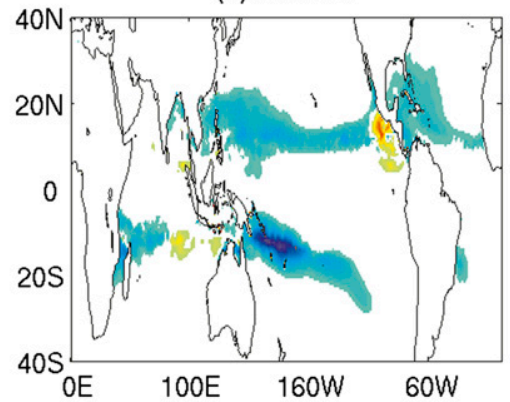

(e) GFDL CM20

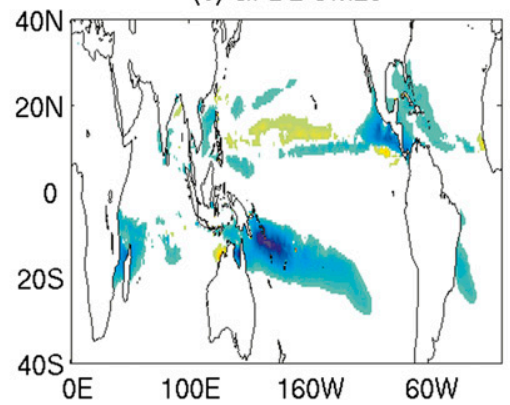

(h) MIROC

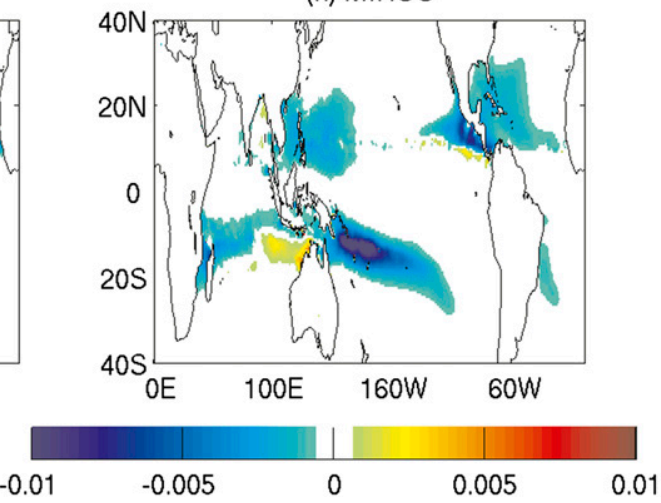

(c) Echam5

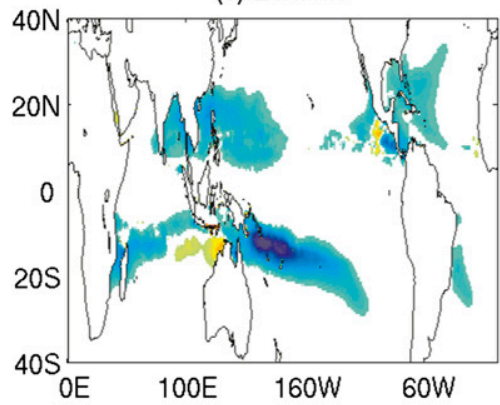

(f) $\mathrm{HadCM} 3$

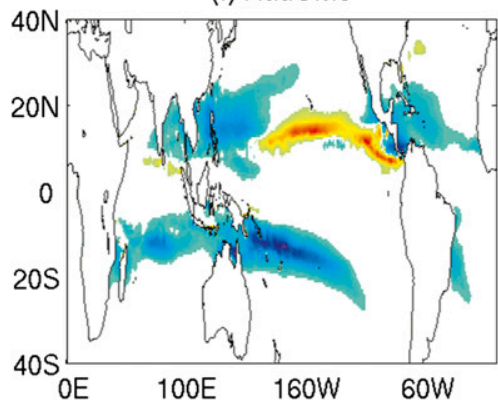

(i) MRI

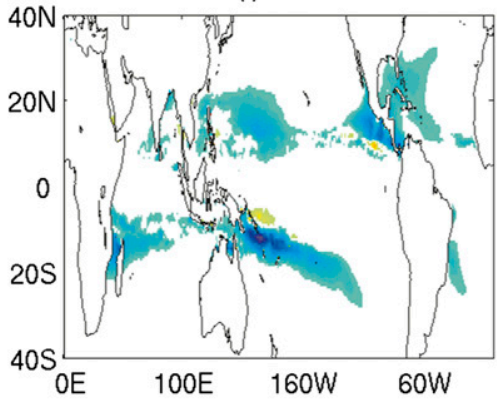

FIG. 12. Difference in the climatology of TCGI-H for the future simulations with different SST anomalies and the present control simulation, using the following as TCGI-H predictors: vorticity, vertical shear, saturation deficit, and potential intensity.

predictors. Instead of using the climatological fields as in all previous cases, we used all 25 years of monthly data in the present climate (i.e., without averaging over all years, when calculating those indices). The resulting coefficients, INTC, and RMSE values are shown in Tables 3, 5, 6, and 7. We can notice that in all cases where we used convective precipitation as a predictor, we obtained an increase in the number of genesis events in future scenarios, independently of the other thermodynamic variable considered.

On the other hand, the indices obtained using the vertical velocity either have a very small decrease or stay nearly constant (RSST) or increase in the global mean (SST and PI), implying a prediction of either almost very small decrease or an increase in the TC frequency. None of them predicts a substantial decrease in the HiRAM TC frequency such as actually occurs in the model. When vertical velocity and RSST are chosen as the predictors, while in most scenarios there is a small decrease of TCGI-H in the South Pacific, there is also an increase of the index in the North Pacific. Together these lead to an overall small decrease or very small increase of the global index, depending mainly on the size and magnitude of the increase in the North Pacific in each scenario. The small decrease in the South Pacific (in size and magnitude) has a greater degree of similarity across all the scenarios.

In summary, when large-scale vertical velocity is used in conjunction with other environmental variables in the 
(a) Southern Hemisphere pNTC per season

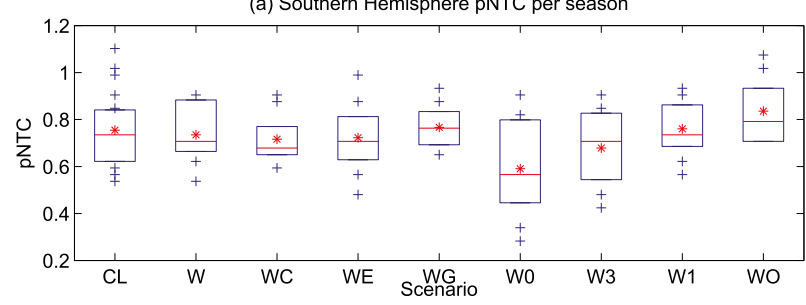

(b) Northern Hemisphere pNTC per season

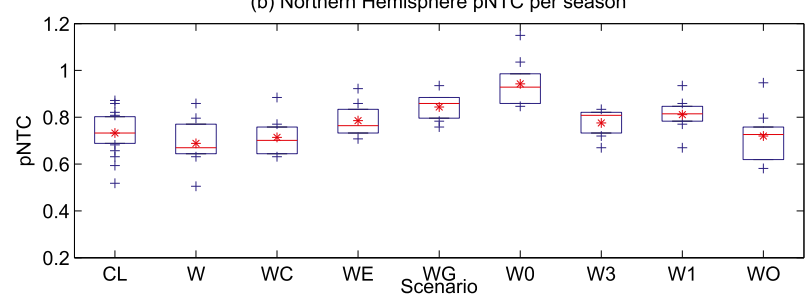

FIG. 13. Box plot of the difference in NTC per year (Southern Hemisphere July-June season) in future scenarios normalized by the mean NTC per hemisphere in the climatological simulation in the (a) Southern and (b) Northern Hemisphere.

construction of an index that is fit to the climatological spatial distribution and seasonal cycle of genesis, the resulting index is unable to predict the global mean changes in NTC in HiRAM. This is the case even though vertical velocity by itself does have a correlation with basin-integrated changes in NTC, as shown in Zhao and Held (2012).

\section{b. Additional cases}

All the future scenarios discussed until now were based on adding spatially and seasonally varying SST anomalies to the SST climatology as the boundary condition for HiRAM. We had available to us two additional simulations. In the first one, the historical climatological (i.e., control) SST is used, while the $\mathrm{CO}_{2}$ concentration in the model was doubled. We call this case $2 \times \mathrm{CO}_{2}$. In the other case, we changed the SST by adding $2 \mathrm{~K}$ uniformly to the SST climatologies, called here plus $2 \mathrm{~K}$ or $\mathrm{p} 2 \mathrm{~K}$, but $\mathrm{CO}_{2}$ was kept constant. These cases were analyzed previously in Held and Zhao (2011) and Zhao and Held (2012); those authors concluded that the changes in the TC activity in the future could be attributed to both the changes in $\mathrm{CO}_{2}$ and to the changes in SST, with a nearly equal contribution from each factor.

Here we examine the TCGI-H predictions for these two scenarios. In both cases, the global NTC is reduced, as shown in Fig. 3. While the climatology of the various TCGI-H indices in the present are very similar to the other cases and to each other, the changes in the future for the indices for these two scenarios are very different from what we obtained in the other scenarios, as shown in 11.

Figure 14 shows the difference between the future and present for the $2 \times \mathrm{CO}_{2}$ scenario using many TCGI-H choices, with various combinations of predictors. Similarly, Fig. 15, shows these differences for the p2K scenario. Figures 14 and 15 are close to being opposites of each other for all panels. While the indices constructed with column relative humidity and PI predict a significant uniform increase in TC activity regions in the future for the $2 \times \mathrm{CO}_{2}$ scenario, there is a very similar decrease in the $\mathrm{p} 2 \mathrm{~K}$ scenario. In contrast, the indices with vertical velocity and convective precipitation show much smaller and sporadic differences, with the values of the indices slightly decreasing for the $2 \times \mathrm{CO}_{2}$ case and slightly increasing in the $\mathrm{p} 2 \mathrm{~K}$ case. It is puzzling how different the changes in the indices are in these two scenarios compared to the changes found in the cases examined above. The INTC for these two cases for various indices is given in Table 5, with the TCGI-H indices including column relative humidity and saturation deficit predicting a large increase in the number of cyclones for the $2 \times \mathrm{CO}_{2}$ simulation and a large decrease in the $\mathrm{p} 2 \mathrm{~K}$ simulation. Only the vertical velocity TCGI-H indices with PI and RSST decrease the INTC for the $2 \times \mathrm{CO}_{2}$ and the p2K simulations; however, the decrease is not large enough, especially for the $\mathrm{p} 2 \mathrm{~K}$ simulation, as shown by the RMSE values (Tables 6 and 7).

In an attempt to diagnose the reason for these disparate results for the $2 \times \mathrm{CO}_{2}$ and $\mathrm{p} 2 \mathrm{~K}$ scenarios, we repeated the Poisson regression procedure for three future scenarios - the warm, $2 \times \mathrm{CO}_{2}$, and $\mathrm{p} 2 \mathrm{~K}$ scenarios-for many combinations of four predictors, as shown in Table 8 . Comparing these with the coefficients obtained when training the TCGI-H in the present climate (Table 3), the warm indices have higher coefficients for the vorticity and thermal coefficients, with the best index obtained with the column relative humidity and SST. In contrast, the $2 \times \mathrm{CO}_{2}$ indices have smaller dependences on the humidity. Finally, the p2K indices have stronger dependence on the vorticity, similar to the warm case, but the thermal coefficients are similar to those of the present climate. The best indices for both the $2 \times \mathrm{CO}_{2}$ and $\mathrm{p} 2 \mathrm{~K}$ scenarios are obtained using the combination of the saturation deficit and the SST. These differences express the different characteristics of the environmental conditions in the $2 \times \mathrm{CO}_{2}$ and $\mathrm{p} 2 \mathrm{~K}$ scenarios when compared with the warm and present climatology.

At this point, we do not have a truly satisfactory explanation for the apparent failure of our index methodology in the case of the $2 \times \mathrm{CO}_{2}$ and $\mathrm{p} 2 \mathrm{~K}$ experiments. At a somewhat superficial level, it seems that our index is more successful when changes in the environment for TCs are caused by climate change with some spatial structure, here imposed through the SST field. This is broadly consistent with arguments based on relative SST; on the other hand, such arguments suggest that 
(a) Column Rel. Humidity \& PI

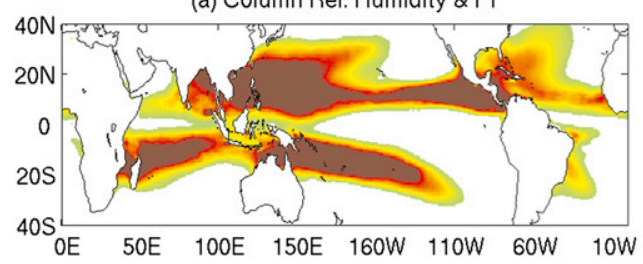

(c) Saturation Deficit \& PI

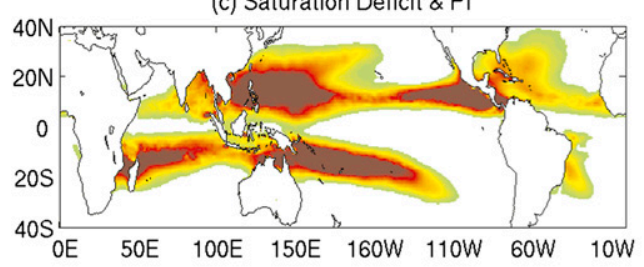

(e) Vertical Velocity \& PI

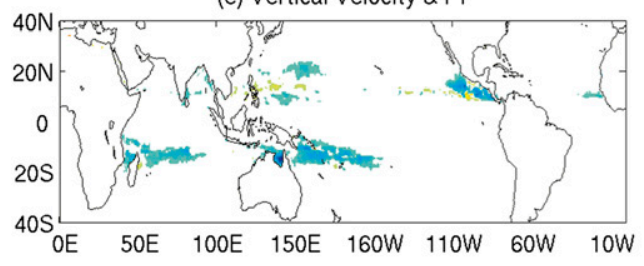

(g) Convective Precipitation \& PI

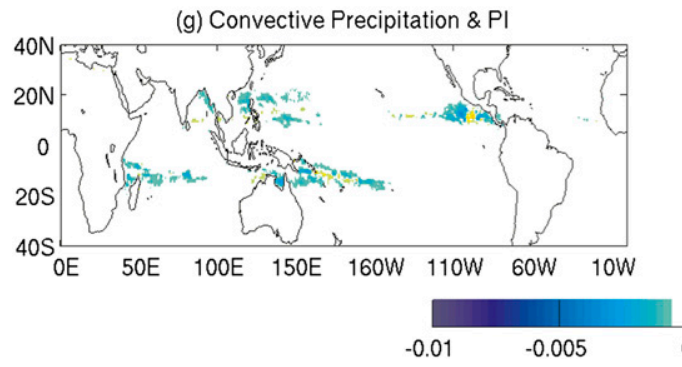

(b) Column Rel. Humidity \& RSST

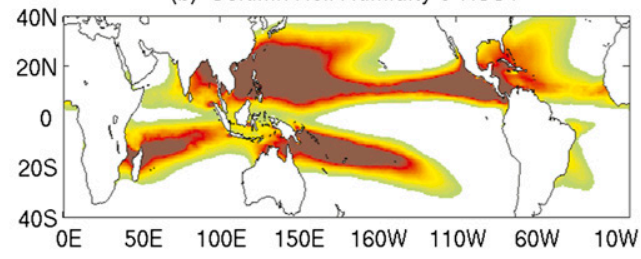

(d) Saturation Deficit \& RSST

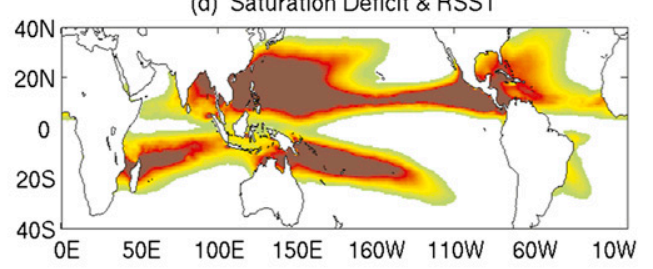

(f) Vertical Velocity \& RSST

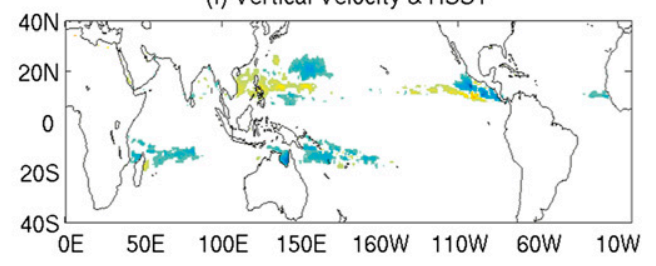

(h) Convective Precipitation \& RSST

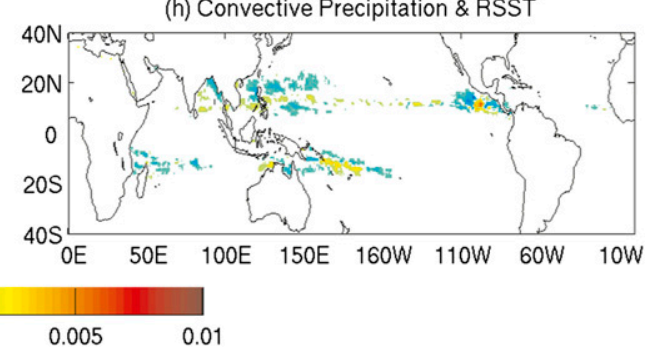

FIG. 14. Difference in the climatology of TCGI-H for the future simulations with double $\mathrm{CO}_{2}$ and the present control simulation, using the following as TCGI-H predictors: vorticity; vertical shear; (a),(b) column relative humidity; (c),(d) saturation deficit; (e),(f) vertical velocity; and (g),(h) convective precipitation, as well as (left) potential intensity or (right) RSST.

there might be cancellation between NTC changes in different regions (since, by definition, relative SST cannot have the same sign everywhere). In this light, the fact that our index-if saturation deficit and PI are chosen as the thermodynamic predictors-is able to capture the global mean change in the various CMIPbased SST scenarios is encouraging. At the same time, our index fails to capture global NTC changes when the imposed forcings, whether SST or $\mathrm{CO}_{2}$, have no spatial structure. We leave this as an open problem for future work.

\section{c. Regional aspects}

The last issue we explore is the regional variations of the indices in the HiRAM simulations. Given that our indices were obtained by using variables and global TC distribution, one does not expect that these indices would perform as well as indices that are trained for specific regions [e.g., North Atlantic genesis indices (Bruyère et al. 2012; Waters et al. 2012)]. In Table 9, we show the mean NTC, mean INTC and their fractional change for two TCGI-H in the present climate and warm scenario for the column relative humidity and RSST, as well as the saturation deficit and PI indices. In the Southern Hemisphere for the present climate, both indices overestimate the activity in the Australian region (AUS) and the South Pacific (SP), as well as the South Atlantic (SA). In contrast, in the south Indian Ocean (SI), the CRH index underestimates the TC activity, while the SD INTC is very similar to the mean NTC in that region. This is reflected in the RMSE values shown in Table 10. Both indices seem to behave better in the Northern Hemisphere, with the value of INTC much closer than the mean NTC in all four basins [north Indian (NI), western North Pacific (WNP), central North Pacific (CNP), and North Atlantic (ATL)], with the 
(a) Column Rel. Humidity \& PI

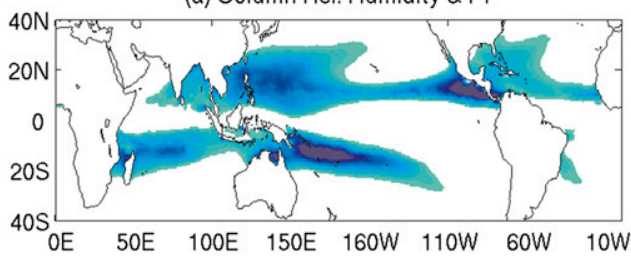

(c) Saturation Deficit \& PI

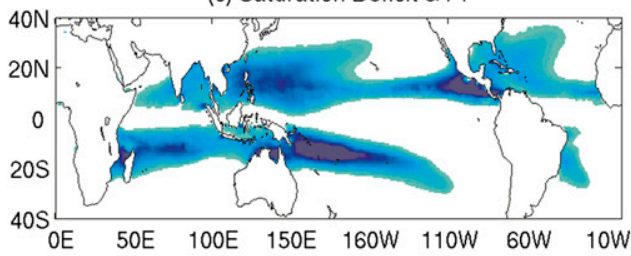

(e) Vertical Velocity \& P

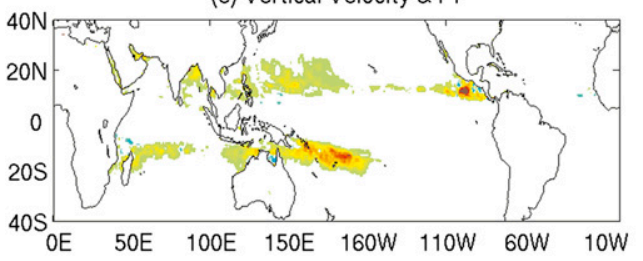

(g) Convective Precipitation \& PI

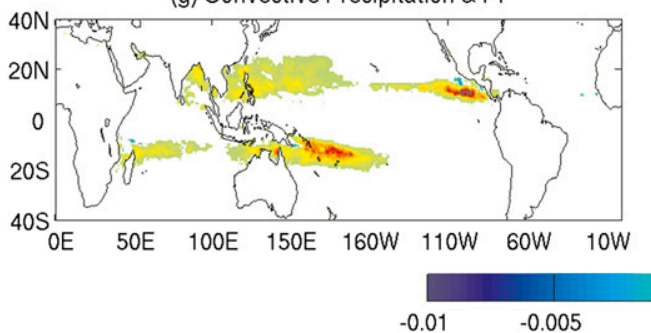

(b) Column Rel. Humidity \& RSST

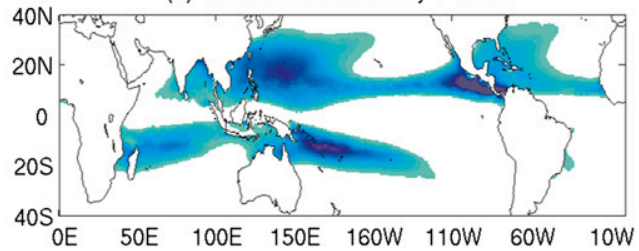

(d) Saturation Deficit \& RSST

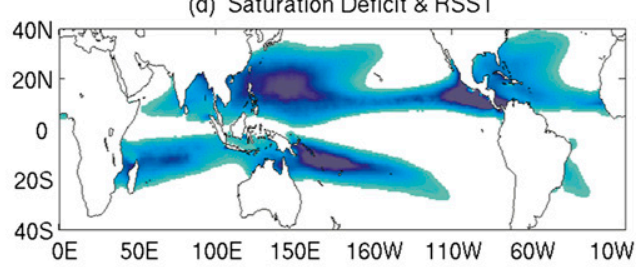

(f) Vertical Velocity \& RSST

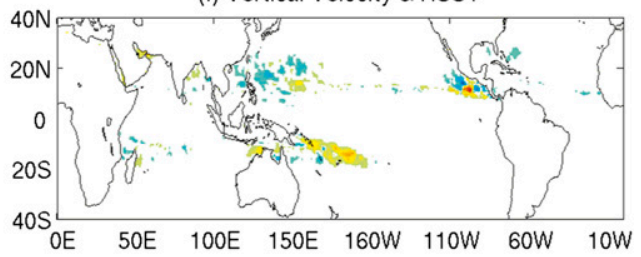

(h) Convective Precipitation \& SST

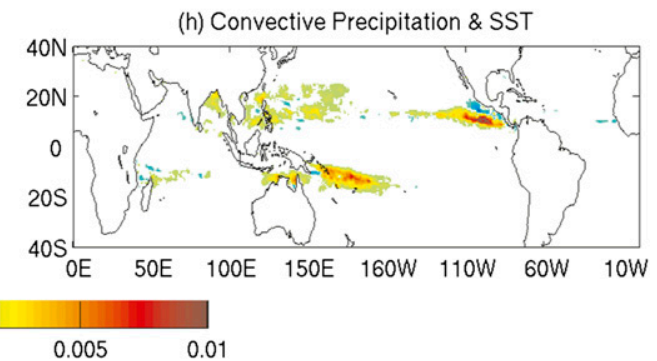

FIG. 15. Difference in the climatology of TCGI-H for the future simulations with $2 \mathrm{~K}$ added uniformly to the SST and the present control simulation, using the following as TCGI-H predictors: vorticity; vertical shear; (a),(b) column relative humidity; (c),(d) saturation deficit; (e),(f) vertical velocity; and (g),(h) convective precipitation, as well as (left) potential intensity or (right) RSST.

largest RMSE occurring in the WNP, which is the basin with the highest NTC globally.

When we consider the INTC and NTC in the warm scenario, as expected from our analysis for the globe, the $\mathrm{CRH}$ index predicts an increase in activity in almost all basins, with the exceptions of the South Pacific and the South Atlantic, where very small decreases are predicted. The RMSE values of the CRH index in the warm scenario increases substantially in most basins, with the exception of the south Indian Ocean. In contrast, the RMSE of the SD index decreases or has smaller increases overall. On the other hand, examining the RMSE of the $\triangle$ INTC (Table 10), it is clear that the SD index has a hard time predicting the changes in the Australian region, the South Pacific, and the eastern North Pacific, where the RMSE values for the CRH are smaller. However, if we consider the fractional changes, the RMSE values of the SD index are smaller than those of the CRH index in all basins, except the eastern North Pacific.

In summary, when we analyze the performance of two of the indices in specific basins, in the present climate, the CRH index performs better, as is expected. However, similarly to the global results, the SD index has a better performance in general, in the warm scenario, as it captures well the magnitude of the decrease of activity that occurs in most basins and the increase in activity in the eastern North Pacific, although it overestimates the mean activity in the Southern Hemisphere.

Genesis indices have been widely used in the climate community as a proxy for TC activity in models globally and regionally. Given that climate models are usually better at simulating the large-scale climate features than they are at simulating the TCs themselves, genesis indices are potentially useful for inferring TC activity in simulated present (e.g., seasonal forecasts) and future 
TABLE 8. Coefficients of the Poisson regression of the TCGI-H using various predictors for the warm simulation $(\mathrm{W})$, the $2 \times \mathrm{CO}_{2}$ simulation and the $\mathrm{p} 2 \mathrm{~K}$ simulation. The humidity factor can be the CRH, the RH, or the SD. The thermal factor can be the SST, the RSST, or the PI.

\begin{tabular}{|c|c|c|c|c|c|c|c|c|}
\hline Type & Index & Vorticity & Humidity & Thermal & Shear & Constant & $\mathrm{AIC} \times 10^{4}$ & $\sigma^{2} \times 10^{4}$ \\
\hline $\mathrm{W}$ & CRH and RSST & 1.42 & 0.10 & 0.35 & -0.13 & -14.89 & 1.9858 & 1.6224 \\
\hline $\mathrm{W}$ & $\mathrm{CRH}$ and SST & 1.47 & 0.09 & 0.37 & -0.13 & -25.74 & 1.9814 & 1.6180 \\
\hline $\mathrm{W}$ & $\mathrm{CRH}$ and PI & 1.64 & 0.11 & 0.08 & -0.13 & -21.46 & 1.9795 & 1.6160 \\
\hline $\mathrm{W}$ & RH and RSST & 1.40 & 0.05 & 0.31 & -0.13 & -11.11 & 2.0056 & 1.6420 \\
\hline $\mathrm{W}$ & $\mathrm{RH}$ and SST & 1.44 & 0.05 & 0.32 & -0.13 & -20.53 & 2.0026 & 1.6389 \\
\hline $\mathrm{W}$ & RH and PI & 1.58 & 0.05 & 0.07 & -0.14 & -16.24 & 2.0019 & 1.6436 \\
\hline $\mathrm{W}$ & SD and RSST & 1.42 & 0.11 & 0.48 & -0.13 & -6.14 & 1.9875 & 1.6241 \\
\hline W & SD and SST & 1.49 & 0.11 & 0.51 & -0.13 & -20.97 & 1.9803 & 1.6169 \\
\hline $\mathrm{W}$ & SD and PI & 1.66 & 0.11 & 0.10 & -0.15 & -13.07 & 1.9910 & 1.6329 \\
\hline $2 \times \mathrm{CO}_{2}$ & $\mathrm{CRH}$ and RSST & 1.24 & 0.08 & 0.42 & -0.12 & -13.97 & 2.6069 & 2.1034 \\
\hline $2 \times \mathrm{CO}_{2}$ & CRH and SST & 1.29 & 0.08 & 0.44 & -0.12 & -26.22 & 2.6014 & 2.0979 \\
\hline $2 \times \mathrm{CO}_{2}$ & $\mathrm{CRH}$ and $\mathrm{PI}$ & 1.46 & 0.09 & 0.09 & -0.13 & -20.74 & 2.6103 & 2.1131 \\
\hline $2 \times \mathrm{CO}_{2}$ & RH and RSST & 1.24 & 0.05 & 0.36 & -0.12 & -10.54 & 2.6157 & 2.1120 \\
\hline $2 \times \mathrm{CO}_{2}$ & RH and SST & 1.28 & 0.05 & 0.37 & -0.12 & -20.77 & 2.6110 & 2.1074 \\
\hline $2 \times \mathrm{CO}_{2}$ & RH and PI & 1.43 & 0.06 & 0.08 & -0.13 & -16.04 & 2.6189 & 2.1205 \\
\hline $2 \times \mathrm{CO}_{2}$ & SD and RSST & 1.24 & 0.10 & 0.51 & -0.12 & -6.34 & 2.6078 & 2.1043 \\
\hline $2 \times \mathrm{CO}_{2}$ & SD and SST & 1.31 & 0.11 & 0.54 & -0.13 & -21.03 & 2.6005 & 2.0970 \\
\hline $2 \times \mathrm{CO}_{2}$ & SD and PI & 1.48 & 0.12 & 0.10 & -0.14 & -12.74 & 2.6194 & 2.1259 \\
\hline $\mathrm{p} 2 \mathrm{~K}$ & CRH and RSST & 1.33 & 0.11 & 0.35 & -0.13 & -14.28 & 2.6041 & 2.1026 \\
\hline $\mathrm{p} 2 \mathrm{~K}$ & $\mathrm{CRH}$ and SST & 1.37 & 0.11 & 0.36 & -0.13 & -24.99 & 2.6008 & 2.0993 \\
\hline $\mathrm{p} 2 \mathrm{~K}$ & $\mathrm{CRH}$ and PI & 1.52 & 0.12 & 0.07 & -0.13 & -20.17 & 2.6203 & 2.1150 \\
\hline $\mathrm{p} 2 \mathrm{~K}$ & RH and RSST & 1.30 & 0.05 & 0.32 & -0.13 & -10.74 & 2.6243 & 2.1226 \\
\hline $\mathrm{p} 2 \mathrm{~K}$ & RH and SST & 1.34 & 0.05 & 0.32 & -0.13 & -20.29 & 2.6216 & 2.1199 \\
\hline $\mathrm{p} 2 \mathrm{~K}$ & $\mathrm{RH}$ and PI & 1.49 & 0.06 & 0.07 & -0.13 & -16.03 & 2.6307 & 2.1336 \\
\hline $\mathrm{p} 2 \mathrm{~K}$ & SD and RSST & 1.34 & 0.12 & 0.55 & -0.13 & -4.00 & 2.6072 & 2.1058 \\
\hline $\mathrm{p} 2 \mathrm{~K}$ & SD and SST & 1.41 & 0.13 & 0.57 & -0.13 & -20.67 & 2.6003 & 2.0988 \\
\hline $\mathrm{p} 2 \mathrm{~K}$ & SD and PI & 1.55 & 0.09 & 0.10 & -0.16 & -12.02 & 2.6312 & 2.1643 \\
\hline
\end{tabular}

climates. However, it has been shown that the relationship of models' own TCs and genesis indices computed from the same models' large-scale fields is not optimal; a strong relationship between them occurs only in specific cases [e.g., in some basins and models (Camargo et al. 2007b) for low-resolution climate models]. In the case of genesis indices developed specifically for the North Atlantic, a relationship between the genesis index and the number of TCs is only valid when smaller subbasins are considered (Bruyère et al. 2012) or when incorporating medium-to-high-frequency variability (Waters et al. 2012).
Regional comparisons of genesis indices and regional climate models have also be shown to be successful in some cases (Chauvin et al. 2006; Jourdain et al. 2011). Walsh et al. (2010) found that the agreement between one genesis index (GPI) and model TCs tended to increase with model resolution.

\section{Discussion}

In this study, we explored the relationship of objectively derived genesis indices to the frequency of TCs

TABLE 9. Mean NTC ( $\overline{\mathrm{NTC}})$ per basin over all years in the present climate and in the warm HiRAM simulations and mean INTC (INTC) predicted using two versions of the HiRAM index TCGI-H (with different predictors) and their fractional change. In the Southern Hemisphere basins, the number of TCs is calculated in the period July-June, while in the Northern Hemisphere, the calendar year is used.

\begin{tabular}{|c|c|c|c|c|c|c|c|c|c|c|c|}
\hline & Quantity & Type & SI & AUS & SP & NI & WNP & $\mathrm{CNP}$ & ENP & ATL & SA \\
\hline HiRAM & $\overline{\text { NTC }}$ & $\mathrm{CL}$ & 18.2 & 8.3 & 8.2 & 6.8 & 36.8 & 4.9 & 18.6 & 12.1 & 0.7 \\
\hline HiRAM & $\overline{\mathrm{NTC}}$ & W & 14.2 & 6.3 & 4.9 & 6.5 & 22.4 & 1.5 & 22.8 & 7.8 & 0.6 \\
\hline HiRAM & FC & W & -0.22 & -0.24 & -0.40 & -0.04 & -0.39 & -0.69 & 0.23 & -0.35 & -0.17 \\
\hline $\mathrm{CRH}$ and RSST & $\overline{\mathrm{INTC}}$ & $\mathrm{CL}$ & 13.0 & 11.7 & 16.1 & 5.4 & 39.5 & 6.6 & 15.7 & 14.6 & 1.5 \\
\hline CRH and RSST & $\overline{\text { INTC }}$ & W & 15.3 & 14.0 & 15.4 & 7.1 & 51.2 & 9.0 & 20.2 & 14.6 & 1.4 \\
\hline $\mathrm{CRH}$ and RSST & $\mathrm{FC}$ & $\mathrm{W}$ & 0.18 & 0.20 & -0.04 & 0.32 & 0.29 & 0.36 & 0.29 & 0.00 & -0.04 \\
\hline SD and PI & $\overline{\text { INTC }}$ & $\mathrm{CL}$ & 18.7 & 22.3 & 26.4 & 7.5 & 32.1 & 5.9 & 15.0 & 15.3 & 3.2 \\
\hline SD and PI & $\overline{\mathrm{INTC}}$ & W & 15.5 & 16.5 & 16.2 & 6.5 & 24.3 & 3.4 & 15.7 & 8.8 & 2.0 \\
\hline SD and PI & $\mathrm{FC}$ & $\mathrm{W}$ & -0.17 & -0.26 & -0.39 & -0.13 & -0.24 & -0.42 & 0.04 & -0.42 & -0.38 \\
\hline
\end{tabular}


TABLE 10. RMSE between the NTC and INTC per year in each basin in CL and in the warm HiRAM simulations using two versions of the HiRAM index TCGI-H (with different predictors). RMSE between the difference and the FC of the mean NTC and mean INTC per basin in the HiRAM simulation predicted using the two versions of the HiRAM index TCGI-H (with different predictors) for all warm simulations.

\begin{tabular}{|c|c|c|c|c|c|c|c|c|c|c|c|}
\hline Index & RMS & Type & SI & AUS & SP & NI & WNP & CNP & ENP & ATL & SA \\
\hline CRH and RSST & NTC & $\mathrm{CL}$ & 6.3 & 4.0 & 8.3 & 2.2 & 6.8 & 2.6 & 4.4 & 3.7 & 1.0 \\
\hline CRH and RSST & NTC & $\mathrm{W}$ & 2.6 & 7.7 & 10.5 & 2.3 & 26.6 & 4.3 & 4.9 & 6.5 & 1.3 \\
\hline SD and PI & NTC & $\mathrm{CL}$ & 3.7 & 14.3 & 18.5 & 2.0 & 8.2 & 2.2 & 5.1 & 4.2 & 2.6 \\
\hline SD and PI & NTC & $\mathrm{W}$ & 4.9 & 14.2 & 13.7 & 2.4 & 9.5 & 2.3 & 5.0 & 4.4 & 2.2 \\
\hline CRH and RSST & $\Delta$ & All W & 5.2 & 2.9 & 3.1 & 2.6 & 15.3 & 4.3 & 3.1 & 3.6 & 0.3 \\
\hline SD and PI & $\Delta$ & All W & 2.2 & 4.2 & 8.8 & 1.2 & 7.6 & 3.6 & 4.9 & 3.9 & 1.3 \\
\hline $\mathrm{CRH}$ and RSST & $\mathrm{FC}$ & All W & 0.30 & 0.30 & 0.34 & 0.43 & 0.41 & 0.74 & 0.17 & 0.30 & 0.47 \\
\hline SD and PI & FC & All W & 0.12 & 0.11 & 0.28 & 0.16 & 0.21 & 0.71 & 0.29 & 0.27 & 0.27 \\
\hline
\end{tabular}

simulated by a high-resolution atmospheric model. We used a previously developed methodology that allows us to derive genesis indices easily and reproducibly from environmental fields (from reanalysis or model output) and TC frequency (from observations or models). Our goals were both to test the methodology used to derive the index for its applicability to the climate change problem and to look for further insights into the reasons for the global mean decrease in TC number in the model under SST changes derived from greenhouse gas-forced warming scenarios.

Our primary conclusions are as follow:

(i) Many genesis indices developed for the present climatology are not able to capture the reduction of global TC activity in a warmer world, at least within the context of HiRAM. A successful fit to the present climatology, or even success in interannual prediction or other independent data, is not a guarantee that the index will capture the response to greenhouse gasinduced warming.

(ii) Our results suggest that the global reduction in TC frequency in warmer climates simulated by HiRAM is attributable to the increasing saturation deficit, as temperature increases while relative humidity stays close to constant. This effect is partly compensated by increases in PI, which reduce the magnitude of the decrease in TC frequency.

(iii) Our results show the value of an objective and reproducible method to derive genesis indices, as derived in Tippett et al. (2011). As either new observations of TCs Landsea et al. $(2008,2012)$ or large-scale fields (or both) become available or new insights emerge regarding which environmental variables are important to genesis, our methodology will allow us to derive better indices.

(iv) However, our methodology fails here to capture the global TC changes found in which the forcingseither SST or $\mathrm{CO}_{2}$ - have no spatial structure. At present, we do not understand whether this is a failure of the index methodology itself, a poor choice of predictors, or some other issue.

By highlighting the role of the saturation deficit, our analysis suggests that that thermodynamic parameter is an important factor in the decrease in NTC predicted in the warming scenarios by HiRAM (at least those for which the index performs well; that is, all but those with spatially uniform forcings). Our analysis does not, on the other hand, provide any independent evidence as to whether that decrease predicted by HiRAM is correct. At least one set of results using a high-resolution downscaling technique (Emanuel 2013) and various genesis indices applied directly to fields from lower-resolution coupled climate models (Camargo 2013) predict an increase in TC activity under future warming scenarios. It remains possible that the reduction of global TC frequency found in most higher-resolution atmospheric models (Knutson et al. 2010) could be due to common errors in the way those models generate TCs. It is well known that the TC frequency in models is very sensitive to model configuration, especially convection scheme (Vitart and Stockdale 2001; Kim et al. 2012; Reed and Jablonowski 2011; Zhao and Held 2012) and dynamical core (Reed and Jablonowski 2012; Walsh et al. 2013), and the frequency decrease in models could potentially be sensitive to these details. The present study does not resolve this issue. It does show, however, that the application of empirical genesis indices to such questions is not a simple matter. Our results show that many indices that give similar results for the present climate may nonetheless give qualitatively different results for the global mean response of TC number to a forced climate change.

Acknowledgments. This work was supported in part by NOAA Grants NA08OAR4320912 and NA11OAR4300193, NSF Grant AGS 1143959, and ONR Grant N00014-121-0911. We thank the three anonymous reviewers for their comments, which significantly improved this paper. 


\section{REFERENCES}

Akaike, H., 1973: Information theory and an extension of the maximum likelihood principle. Proc. Second Int. Symp. on Information Theory, Budapest, Hungary, Akademiai Kiadó, 267-281.

Bell, R., J. Strachan, P. L. Vidale, K. Hodges, and M. Roberts, 2013: Response of tropical cyclones to idealized climate change experiments in a global high-resolution coupled general circulation model. J. Climate, 26, 7966-7980, doi:10.1175/ JCLI-D-12-00749.1.

Bender, M. A., T. R. Knutson, R. E. Tuleya, J. J. Sirutis, G. A. Vecchi, S. T. Garner, and I. M. Held, 2010: Modeled impact of anthropogenic warming on the frequency of intense Atlantic hurricanes. Science, 327, 454-458, doi:10.1126/science.1180568.

Bengtsson, L., H. Böttger, and M. Kanamitsu, 1982: Simulation of hurricane-type vortices in a general circulation model. Tellus, 34A, 440-457, doi:10.1111/j.2153-3490.1982.tb01833.x.

Bister, M., and K. A. Emanuel, 1998: Dissipative heating and hurricane intensity. Meteor. Atmos. Phys., 65, 233-240, doi:10.1007/BF01030791.

$\longrightarrow$, and ——, 2002a: Low frequency variability of tropical cyclone potential intensity. 1. Interannual to interdecadal variability. J. Geophys. Res., 107, 4801, doi:10.1029/2001JD000776.

$\longrightarrow$, and,$- 2002 \mathrm{~b}$ : Low frequency variability of tropical cyclone potential intensity. 2. Climatology for 1982-1995. J. Geophys. Res., 107, 4621, doi:10.1029/2001JD000780.

Bretherton, C. S., M. E. Peters, and L. E. Back, 2004: Relationships between water vapor path and precipitation over the tropical oceans. J. Climate, 17, 1517-1528, doi:10.1175/1520-0442(2004)017<1517: RBWVPA $>2.0 . \mathrm{CO} ; 2$.

Bruyère, C. L., G. J. Holland, and E. Towler, 2012: Investigating the use of a genesis potential index for tropical cyclones in the North Atlantic basin. J. Climate, 25, 8611-8626, doi:10.1175/ JCLI-D-11-00619.1.

Bye, J., and K. Keay, 2008: A new hurricane index for the Caribbean. Interciencia, 33, 556-560.

Camargo, S. J., 2013: Global and regional aspects of tropical cyclone activity in the CMIP5 models. J. Climate, 26, 9880-9902, doi:10.1175/JCLI-D-12-00549.1.

— A. A. Barnston, and S. E. Zebiak, 2005: A statistical assessment of tropical cyclones in atmospheric general circulation models. Tellus, 57A, 589-604, doi:10.1111/j.1600-0870.2005.00117.x.

- H. Li, and L. Sun, 2007a: Feasibility study for downscaling seasonal tropical cyclone activity using the NCEP regional spectral model. Int. J. Climatol., 27, 311-325, doi:10.1002/ joc. 1400 .

— A. H. Sobel, A. G. Barnston, and K. A. Emanuel, 2007b: Tropical cyclone genesis potential index in climate models. Tellus, 59A, 428-443, doi:10.1111/j.1600-0870.2007.00238.x.

— M. C. Wheeler, and A. H. Sobel, 2009: Diagnosis of the MJO modulation of tropical cyclogenesis using an empirical index. J. Atmos. Sci., 66, 3061-3074, doi:10.1175/2009JAS3101.1.

Cameron, A. C., and F. A. G. Windmeijer, 1996: $R$-squared measure for count data regression models with applications to health-care utilization. J. Bus. Econ. Stat., 14, 209-220.

Chauvin, F., J.-F. Royer, and M. Déqué, 2006: Response of hurricane-type vortices to global warming as simulated by ARPEGE-Climat at high resolution. Climate Dyn., 27, 377399, doi:10.1007/s00382-006-0135-7.

Delworth, T. L., and Coauthors, 2012: Simulated climate and climate change in the GFDL CM2.5 high-resolution coupled climate model. J. Climate, 25, 2755-2781, doi:10.1175/JCLI-D-11-00316.1.
DeMaria, M., J. A. Knaff, and B. H. Conell, 2001: A tropical cyclone genesis parameter for the tropical Atlantic. Wea. Forecasting, 16, 219-233, doi:10.1175/1520-0434(2001)016<0219: ATCGPF $>2.0 . \mathrm{CO} ; 2$.

Emanuel, K. A., 1995: Sensitivity of tropical cyclones to surface exchange coefficients and a revised steady-state model incorporating eye dynamics. J. Atmos. Sci., 52, 3969-3976, doi:10.1175/1520-0469(1995)052<3969:SOTCTS >2.0.CO;2.

_ 2006 : Climate and tropical cyclone activity: A new model downscaling approach. J. Climate, 19, 4797-4802, doi:10.1175/ JCLI3908.1.

- 2010: Tropical cyclone activity downscaled from NOAACIRES reanalysis, 1908-1958. J. Adv. Model. Earth Syst., 2 (1), doi:10.3894/JAMES.2010.2.1.

_ 2013: Downscaling CMIP5 climate models shows increased tropical cyclone activity over the 21st century. Proc. Natl. Acad. Sci. USA, 110, 12 219-12224, doi:10.1073/pnas.1301293110.

— climate. Extended Abstracts, 26th Conf. on Hurricanes and Tropical Meteorology, Miami, FL, Amer. Meteor. Soc., 240 241. [Available online at https://ams.confex.com/ams/26HURR/ techprogram/paper_75463.htm.]

—, S. Ravela, E. Vivant, and C. Risi, 2006: A statistical deterministic approach to hurricane risk assessment. Bull. Amer. Meteor. Soc., 87, 299-314, doi:10.1175/BAMS-87-3-299.

_, R. Sundararajan, and J. Williams, 2008: Hurricanes and global warming: Results from downscaling IPCC AR4 simulations. Bull. Amer. Meteor. Soc., 89, 347-367, doi:10.1175/ BAMS-89-3-347.

Gray, W. M., 1979: Hurricanes: Their formation, structure and likely role in the tropical circulation. Meteorology over the Tropical Oceans, D. B. Shaw, Ed., Royal Meteorological Society, 155-218.

Held, I. M., and M. Zhao, 2011: The response of tropical cyclone statistics to an increase in $\mathrm{CO}_{2}$ with fixed sea surface temperatures. J. Climate, 24, 5353-5364, doi:10.1175/JCLI-D-11-00050.1.

Holland, G., and C. Bruyère, 2014: Recent intense hurricane response to global climate change. Climate Dyn., 42, 617-627, doi:10.1007/s00382-013-1713-0.

Johnson, N. C., and S.-P. Xie, 2010: Changes in the sea surface temperature threshold for tropical convection. Nat. Geosci., 3 , 842-845, doi:10.1038/ngeo1008.

Jourdain, N. C., P. Marchesiello, C. E. Menkes, J. Lefévre, E. M. Vincent, M. Lengaigne, and F. Chauvin, 2011: Mesoscale simulation of tropical cyclones in the South Pacific: Climatology and interannual variability. J. Climate, 24, 3-25, doi:10.1175/2010JCLI3559.1.

JTWC, cited 2013: Joint typhoon warning center tropical cyclone best track data site. [Available online at http://www.usno. navy.mil/NOOC/nmfc-ph/RSS/jtwc/best_tracks/.]

Kalnay, E., and Coauthors, 1996: The NCEP/NCAR 40-Year Reanalysis Project. Bull. Amer. Meteor. Soc., 77, 437-441, doi:10.1175/1520-0477(1996)077<0437:TNYRP>2.0.CO;2.

Kim, D., A. H. Sobel, A. D. Del Genio, Y. Chen, S. J. Camargo, M.-S. Yao, M. Kelley, and L. Nazarenko, 2012: The tropical subseasonal variability simulated in the NASA GISS general circulation model. J. Climate, 25, 4641-4659, doi:10.1175/ JCLI-D-11-00447.1.

Kim, H.-S., G. A. Vecchi, T. Knutson, W. G. Anderson, T. L. Delworth, A. Rosati, F. Zeng, and M. Zhao, 2014: Tropical cyclone simulation and response to $\mathrm{CO}_{2}$ doubling in the GFDL CM2.5 high-resolution coupled climate model. J. Climate, 27, 8034-8054, doi:10.1175/JCLI-D-13-00475.1. 
Kistler, R., and Coauthors, 2001: The NCEP-NCAR 50-Year Reanalysis: Monthly means CD-ROM and documentation. Bull. Amer. Meteor. Soc., 82, 247-267, doi:10.1175/ 1520-0477(2001)082<0247:TNNYRM>2.3.CO;2.

Knutson, T. R., J. J. Sirutis, S. T. Garner, I. M. Held, and R. E. Tuleya, 2007: Simulation of the recent multidecadal increase of Atlantic hurricane activity using an 18-km-grid regional model. Bull. Amer. Meteor. Soc., 88, 1549-1565, doi:10.1175/ BAMS-88-10-1549.

,,,--- G. A. Vecchi, and I. M. Held, 2008: Simulated reduction in Atlantic hurricane frequency under twenty-firstcentury warming conditions. Nat. Geosci., 1,359-364, doi:10.1038/ ngeo202.

—- and Coauthors, 2010: Tropical cyclones and climate change. Nat. Geosci., 3, 157-163, doi:10.1038/ngeo779.

Kotal, S. D., P. K. Kundu, and S. K. R. Bhowmik, 2009: Analysis of cyclogenesis parameter for developing and nondeveloping low-pressure systems over the Indian Sea. Nat. Hazards, 50, 389-402, doi:10.1007/s11069-009-9348-5.

Landman, W. A., A. Seth, and S. J. Camargo, 2005: The effect of regional climate model domain choice on the simulation of tropical cyclone-like vortices in the southwestern Indian Ocean. J. Climate, 18, 1263-1274, doi:10.1175/JCLI3324.1.

Landsea, C. W., and Coauthors, 2008: A reanalysis of the 1911-20 Atlantic hurricane database. J. Climate, 21, 2138-2168, doi:10.1175/2007JCLI1119.1.

—, S. Feuer, A. Hagen, D. A. Glenn, J. Sims, R. Perez, M. Chenoweth, and N. Anderson, 2012: A reanalysis of the 1921-30 Atlantic hurricane database. J. Climate, 25, 865-885, doi:10.1175/JCLI-D-11-00026.1.

Lyon, B., and S. J. Camargo, 2009: The seasonally-varying influence of ENSO on rainfall and tropical cyclone activity in the Philippines. Climate Dyn., 32, 125-141, doi:10.1007/ s00382-008-0380-z.

Menkes, C. E., M. Lengaigne, P. Marchesiello, N. C. Jourdain, E. M. Vincent, J. Lefèvre, F. Chauvin, and J.-F. Royer, 2012: Comparison of tropical cyclonegenesis indices on seasonal to interannual timescales. Climate Dyn., 38, 301-321, doi:10.1007/ s00382-011-1126-x.

Murakami, H., and B. Wang, 2010: Future change of North Atlantic tropical cyclone tracks: Projection by a $20-\mathrm{km}-\mathrm{mesh}$ global atmospheric model. J. Climate, 23, 2699-2721, doi:10.1175/2010JCLI3338.1.

NHC, cited 2013: National Hurricane Center best track data. [Available online at http://www.nhc.noaa.gov/data/\#hurdat.]

Nolan, D. S., E. D. Rappin, and K. A. Emanuel, 2007: Tropical cyclogenesis sensitivity to environmental parameters in radiativeconvective equilibrium. Quart. J. Roy. Meteor. Soc., 133, 20852107, doi:10.1002/qj.170.

Ramsay, H. A., and A. H. Sobel, 2011: The effects of relative and absolute sea surface temperature on tropical cyclone potential intensity using a single-column model. J. Climate, 24, 183-193, doi:10.1175/2010JCLI3690.1.

Reed, K. A. and C. Jablonowski, 2011: Impact of physical parameterizations on idealized tropical cyclones in the Community Atmosphere Model. Geophys. Res. Lett., 38, L04805, doi:10.1029/2010GL046297.

$\longrightarrow$, and —_, 2012: Idealized tropical cyclone simulations of intermediate complexity: A test case for AGCMs. J. Adv. Model. Earth Syst., 4, M04001, doi:10.1029/2011MS000099.

Roberts, M. J., and Coauthors, 2009: Impact of resolution on the tropical Pacific circulation in a matrix of coupled models. J. Climate, 22, 2541-2556, doi:10.1175/2008JCLI2537.1.
Royer, J.-F., F. Chauvin, B. Timbal, P. Araspin, and D. Grimal, 1998: A GCM study of the impact of greenhouse gas increase on the frequency of occurrence of tropical cyclones. Climatic Change, 38, 307-343, doi:10.1023/A:1005386312622.

Ryan, B. F., I. G. Watterson, and J. L. Evans, 1992: Tropical cyclone frequencies inferred from Gray's yearly genesis parameter: Validation of GCM tropical climates. Geophys. Res. Lett., 19, 1831-1834, doi:10.1029/92GL02149.

Sall, S. M., H. Sauvageot, A. T. Gaye, A. Viltard, and P. de Felice, 2006: A cyclogenesis index for tropical Atlantic off the African coasts. Atmos. Res., 79,123-147, doi:10.1016/j.atmosres.2005.05.004.

Shaevitz, D. A., and Coauthors, 2014: Characteristics of tropical cyclones in high-resolution models in the present climate. $J$. Adv. Model. Earth Syst., doi:10.1002/2014MS000372, in press.

Swanson, K. L., 2008: Nonlocality of Atlantic tropical cyclone intensities. Geochem. Geophys. Geosyst., 9, Q04V01, doi:10.1029/ 2007 GC001844.

Tang, B., and K. Emanuel, 2012: A ventilation index for tropical cyclones. Bull. Amer. Meteor. Soc., 93, 1901-1912, doi:10.1175/ BAMS-D-11-00165.1.

, and S. J. Camargo, 2014: Environmental control of tropical cyclones in CMIP5: A ventilation perspective. J. Adv. Model. Earth Syst., 6, 115-128, doi:10.1002/2013MS000294.

Tippett, M. K., S. J. Camargo, and A. H. Sobel, 2011: A Poisson regression index for tropical cyclone genesis and the role of large-scale vorticity in genesis. J. Climate, 24, 2335-2357, doi:10.1175/2010JCLI3811.1.

, A. H. Sobel, and S. J. Camargo, 2012: Association of U.S. tornado occurrence with monthly environmental parameters. Geophys. Res. Lett., 39, L02801, doi:10.1029/2011GL050368. and J. T. Allen, 2014: An empirical relation between U.S. tornado activity and monthly environmental parameters. $J$. Climate, 27, 2983-2999, doi:10.1175/JCLI-D-13-00345.1.

Tory, K. J., S. S. Chand, R. A. Dare, and J. L. McBride, 2013a: An assessment of a model-, grid-, and basin-independent tropical cyclone detection scheme in selected CMIP3 global climate models. J. Climate, 26, 5508-5522, doi:10.1175/JCLI-D-12-00511.1. , J. L. McBride, H. Ye, and R. A. Dare, 2013b: Projected changes in late-twenty-first-century tropical cyclone frequency in 13 coupled climate models from phase 5 of the Coupled Model Intercomparison Project. J. Climate, 26, 9946 9959, doi:10.1175/JCLI-D-13-00010.1.

Uppala, S. M., and Coauthors, 2005: The ERA-40 Re-Analysis. Quart. J. Roy. Meteor. Soc., 131, 2961-3012, doi:10.1256/qj.04.176.

Vecchi, G. A., and B. J. Soden, 2007: Effect of remote sea surface temperature change on tropical cyclone potential intensity. Nature, 450, 1066-1070, doi:10.1038/nature06423.

—, K. L. Swanson, and B. J. Soden, 2008: Whither hurricane activity? Science, 31, 687-689, doi:10.1126/science.1164396. , M. Zhao, H. Wang, G. Villarini, A. Rosati, A. Kumar, I. M. Held, and R. Gudgel, 2011: Statististical-dynamical predictions of seasonal North Atlantic hurricane activity. Mon. Wea. Rev., 139, 1070-1082, doi:10.1175/2010MWR3499.1.

Villarini, G., and G. A. Vecchi, 2012: Twenty-first-century projections of North Atlantic tropical storms from CMIP5 models. Nat. Climate Change, 2, 604-607, doi:10.1038/nclimate1530.

- and _ 2013: Projected increases in North Atlantic tropical cyclone intensity from CMIP5 models. J. Climate, 26, 32313240, doi:10.1175/JCLI-D-12-00441.1.

Vitart, F., and T. N. Stockdale, 2001: Seasonal forecasting of tropical storms using coupled GCM integrations. Mon. Wea. Rev., 129, 2521-2537, doi:10.1175/1520-0493(2001)129<2521: SFOTSU $>2.0 . \mathrm{CO} ; 2$. 
— J. L. Anderson, and W. F. Stern, 1997: Simulation of interannual variability of tropical storm frequency in an ensemble of GCM integrations. J. Climate, 10, 745-760, doi:10.1175/1520-0442(1997)010<0745:SOIVOT >2.0.CO;2.

— D. Anderson, and T. Stockdale, 2003: Seasonal forecasting of tropical cyclone landfall over Mozambique. J. Climate, 16, 3932-3945, doi:10.1175/1520-0442(2003)016<3932: SFOTCL $>2.0 . C O ; 2$.

Walsh, K., S. Lavender, H. Murakami, E. Scoccimarro, L.-P. Caron, and M. Ghantous, 2010: The Tropical Cyclone climate Model Intercomparison Project. Hurricanes and Climate Change, Vol. 2. Springer Verlag, 1-24.

,-- E. Scoccimarro, and H. Murakami, 2013: Resolution dependence of tropical cyclone formation in CMIP3 and finer resolution models. Climate Dyn., 40, 585-599, doi:10.1007/ s00382-012-1298-z.

Waters, J. J., J. L. Evans, and C. E. Forest, 2012: Large-scale diagnostics of tropical cyclogenesis potential using environment variability metrics and logistic regression models. J. Climate, 25, 6092-6107, doi:10.1175/JCLI-D-11-00359.1.

Wentz, F. J., and R. W. Spencer, 1998: SSM/I rain retrievals within a unified all-weather ocean algorithm. J. Atmos. Sci., 55, 1613-1627, doi:10.1175/1520-0469(1998)055<1613: SIRRWA $>2.0 . \mathrm{CO} ; 2$.
Yokoi, S., and Y. N. Takayabu, 2009: Multi-model projection of global warming impact on tropical cyclone genesis frequency over the western North Pacific. J. Meteor. Soc. Japan, 87, 525538, doi:10.2151/jmsj.87.525.

- — , and J. C. L. Chan, 2009: Tropical cyclone genesis frequency over the western North Pacific simulated in mediumresolution coupled general circulation models. Climate Dyn., 33, 665-683, doi:10.1007/s00382-009-0593-9.

Zhao, M., and I. M. Held, 2010: An analysis of the effect of global warming on the intensity of Atlantic hurricanes using a GCM with statistical refinement. J. Climate, 23, 6382-6393, doi:10.1175/2010JCLI3837.1.

— and - 2012: TC-permitting GCM simulations of hurricane frequency response to sea surface temperature anomalies projected for the late-twenty-first century. J. Climate, 25, 2995-3009, doi:10.1175/JCLI-D-11-00313.1. , S.-J. Lin, and G. A. Vecchi, 2009: Simulations of global hurricane climatology, interannual variability, and response to global warming using a 50-km resolution GCM. J. Climate, 22, 6653-6678, doi:10.1175/2009JCLI3049.1.

, _ - and G. A. Vecchi, 2010: Retrospective forecasts of the hurricane season using a global atmospheric model assuming persistence of SST anomalies. Mon. Wea. Rev., 138, 38583868, doi:10.1175/2010MWR3366.1. 